\title{
UNA EXTENSIÓN ENTRE EL ALTIPLANO Y EL MAR. RELATOS MÍTICOS CHIPAYA Y EL NORTE DE CHILE
}

\author{
Verónica Cereceda ${ }^{1}$
}

\section{* Introducción}

Resumen

A partir de la recopilación y análisis semiótico de relatos orales provenientes de la localidad de Chipaya (depto. de Oruro, Bolivia), y específicamente de narraciones asociadas a las conductas y recorridos de los vientos soqo, a los comportamientos y desplazamiento de otras divinidades como el saqra, y a los roles ejercidos por determinados santos cristianos, se configura y reconstituye un espacio mítico y un paisaje ancestral que, aunque supera con creces sus actuales límites territoriales, define e identifica a los chipaya dentro de un espacio simbólico mayor.

Palabras claves: Chipaya - mitos - soqo - saqra - espacios simbólicos. Abstract
After collecting and semiotic analyzing oral stories from Chipaya
(dept. of Oruro, Bolivia), specifically those associated with the
winds soqo; behaviors and displacement of other deities as the saqra,
and with roles exercised by certain Christian saints, is set up and
reconstituted a mythical space and ancestral landscape, but far
exceeds its current boundaries, defines and identifies chipaya
symbolic space within a larger one.

Key words: Chipaya - myth - soqo - saqra - symbolic spaces.

Recibido: julio 2010. Aceptado: agosto 2010.
Durante mis estadías en la comunidad de Chipaya (depto. de Oruro, Bolivia) en 1982 y 1985 , pude recoger una serie de relatos de naturaleza mítica con distintos temas. ${ }^{2}$ En un comienzo, pensé en escribir simples notas, pero en la medida en que me adentraba más y más en su lectura, se fue haciendo evidente la presencia de lo que podría llamar una transtextualidad. Algunos datos secundarios, y que surgen en las diferentes historias, iban dibujando una imagen: la imagen de un vasto territorio que se va construyendo en nuestra mente cuando se suman varios textos con sus puntos límites, sus articulaciones, sus cargas semánticas que van priorizando algunos lugares y olvidando otros. Como un efecto cinematográfico o como la visión aérea de un amplio panorama, los relatos míticos -además de su sentido específico- parecían proponerse una tarea común, la de diseñar un mapa ecológico y geográfico. Era posible percibir que los diferentes textos se estaban haciendo referencia o aludiendo los unos a los otros, pero esta referencia constituía una suerte de texto aparte, un nuevo mito no narrado como tal, pero presente en el pensamiento de aquellos que dominan los relatos como un conjunto.

Si bien, por ejemplo, las historias de los vientos que se incluían entre los relatos recogidos podían ser entendidas, desde una perspectiva, como una unidad de sentido (con la condición, al menos, de ponerlas en relación las unas con las otras), estaba allí la presencia callada de un texto más amplio, de un mito englobante cuyo resultado es la imagen de un espacio.

\footnotetext{
1 Antropólogos del Surandino (ASUR). Casilla 667, Sucre, BOLIVIA. Email: veronicacereceda@gmail.com

2 Estos relatos, unidos a los que había recogido mi amiga lingüista Lilianne Porterie-Gutiérrez (1990), conformaban un corpus muy interesante. Reuníamos entre las dos distintas versiones en español, aymara o chipay taku, de un mismo relato. Nos propusimos un trabajo conjunto que no pudimos realizar por la brusca partida de Lilianne. Escribí un primer texto en su memoria (Cereceda 1993). Esta es la primera versión en español de aquel texto, con algunas modificaciones.
} 
Se me plantearon, entonces, algunos problemas. El primero de ellos se relaciona con el derecho a "ser" de este mito mental, es decir, el de su construcción semiótica. ¿Qué nos autoriza a considerar que esta imagen forma un nuevo texto si no hay palabras específicas, directas, que lo vayan narrando? ¿Es posible dilucidar un programa narrativo que le sea propio y que le conceda existencia como un conjunto significante, aunque su presencia esté formada solo de relaciones, de sugerencias? El segundo se relaciona con su sentido: ¿a qué corresponde ese espacio, qué papel desempeña? El vasto territorio que los diferentes relatos componen como un mapa único, no sigue ni los límites de la comunidad ni parece tampoco corresponder al conocimiento práctico actual de un paisaje dominado por el grupo étnico.

Fue la intuición de esa imagen espacial la que fue ordenando los relatos. La exposición sigue los pasos del desarrollo de la reflexión, es decir, empecé con los vientos como si ellos fuesen el tema, ya que en las invocaciones en una ceremonia dedicada a ellos, el norte de Chile surgía con toda su fuerza de paisaje conocido y amado. Incluso los dos primeros relatos de los vientos, que aparecen como intrascendentes y que aparentemente tratan de asuntos muy distintos, fueron los que primero me permitieron presentir que los escenarios descritos -como sin necesidad para el desenvolvimiento de las acciones- tenían un sentido propio. Y luego, la ceremonia encadenó los vientos con las historias de otros personajes sagrados, y así fue surgiendo la presencia de un mapa cuya existencia no se narra directamente como un relato específico, sino solo con alusiones al interior de otras historias.

Pero también son los vientos los que me sugirieron la lectura de un contenido que no se insinúa tan explícito en los relatos de otras deidades: un contenido de identidad. Diríamos que las historias de los vientos, a través de una serie de procedimientos discursivos, permiten enlazar historias ocurridas quizás cuándo y a seres intangibles hoy, con los chipaya actuales y reales. Ellos se convierten, a través de esta relación provocada por las historias de vientos, no solo en enunciadores del mito, como es lo natural, sino en actores concretos al interior de la narración. De modo que empezaremos por las historias de los vientos.

Habría que recordar que Chipaya -ubicado en el altiplano de Oruro, muy cerca de la frontera con Chile- es un ayllu de origen uru (Figura 1). ${ }^{3}$ Los uru eran pueblos que a la llegada de los españoles se encontraban en situación marginal, aunque con un desarrollo poblacional muy superior al actual. ${ }^{4}$ Habitaban las riberas de ríos y lagos, dedicándose solo a la pesca y a la caza, casi sin agricultura. Fueron considerados por los colonizadores como mucho más salvajes, menos civilizados y menos inteligentes que los aymara..$^{5}$ Los chipaya conservan hasta nuestros días una variante de la lengua uru, lengua que se hablaba también en los bordes de los lagos Titicaca y Poopó y que ellos llaman chipay taku. Como todos los pueblos actuales de origen uru, se dicen herederos directos de una humanidad previa o prehumanidad que se quemó con el nacimiento del Sol y de la cual algunos se salvaron lanzándose a las aguas del río Lauca o a otros ríos y lagos. Es decir, se consideran descendientes de los chullpa, palabra que designa tanto en quechua, aymara como en chipay taku a los que vivieron en una época primera, oscura, sin Sol.

Muchos chipaya se aventuran hoy hacia Chile a realizar trabajos temporales en las chacras de Chiapa, Camiña y otros valles $y$, por lo menos, hace unos 30 años todavía había enclaves chipaya en el ayllu Isluga, hoy territorio chileno. Pero, como surge de los relatos, los chipaya parecen haber dominado en el pasado un paisaje mucho más amplio que el que hoy habitan, que se extendía, posiblemente, hasta los bordes mismos del océano Pacífico. Se generan así, además de los problemas antropológicos que plantean estos relatos, no solo preguntas sobre una posible memoria de más de 400 años de duración, sino también sobre las

\footnotetext{
3 El pueblo de Chipaya se encuentra al suroeste del altiplano de Oruro, casi frente al ayllu aymara de Isluga, ubicado en territorio chileno. El río Lauca atraviesa el pueblo y lo divide en mitades que, a su vez, dan origen en el plano estructural, a las mitades de arriba y de abajo, Twanta y Tajata.

4 En el momento de la visita de Toledo, se registran numerosos asentamientos uru, hoy desaparecidos, no solamente los más conocidos del río Desaguadero y de los contornos del lago Titicaca, sino también en la cadena de lagunas, incluso en Lípez y otros lugares, aunque siempre con una población minoritaria en relación a la población aymara (Bouysse-Cassagne 1975:312; Wachtel 1978: 1127).

5 Muchas son las expresiones españolas que definieron a los uru como pueblos retrasados o no aptos para algunas labores: “...son todos pobres porque no tienen ganado. Viven en las riberas de las lagunas donde pescan, con lo que se sustentan y andan rotos y desnudos por no quererse aplicar a trabajar [...] y hay muchos que están dentro de las lagunas sin hacer sementeras ni ropas comiendo unas raíces que llaman totora..." (Diez de San Miguel 1964 [1567]: 209). Entre otras muchas expresiones, ver también Vellard (1954).
} 


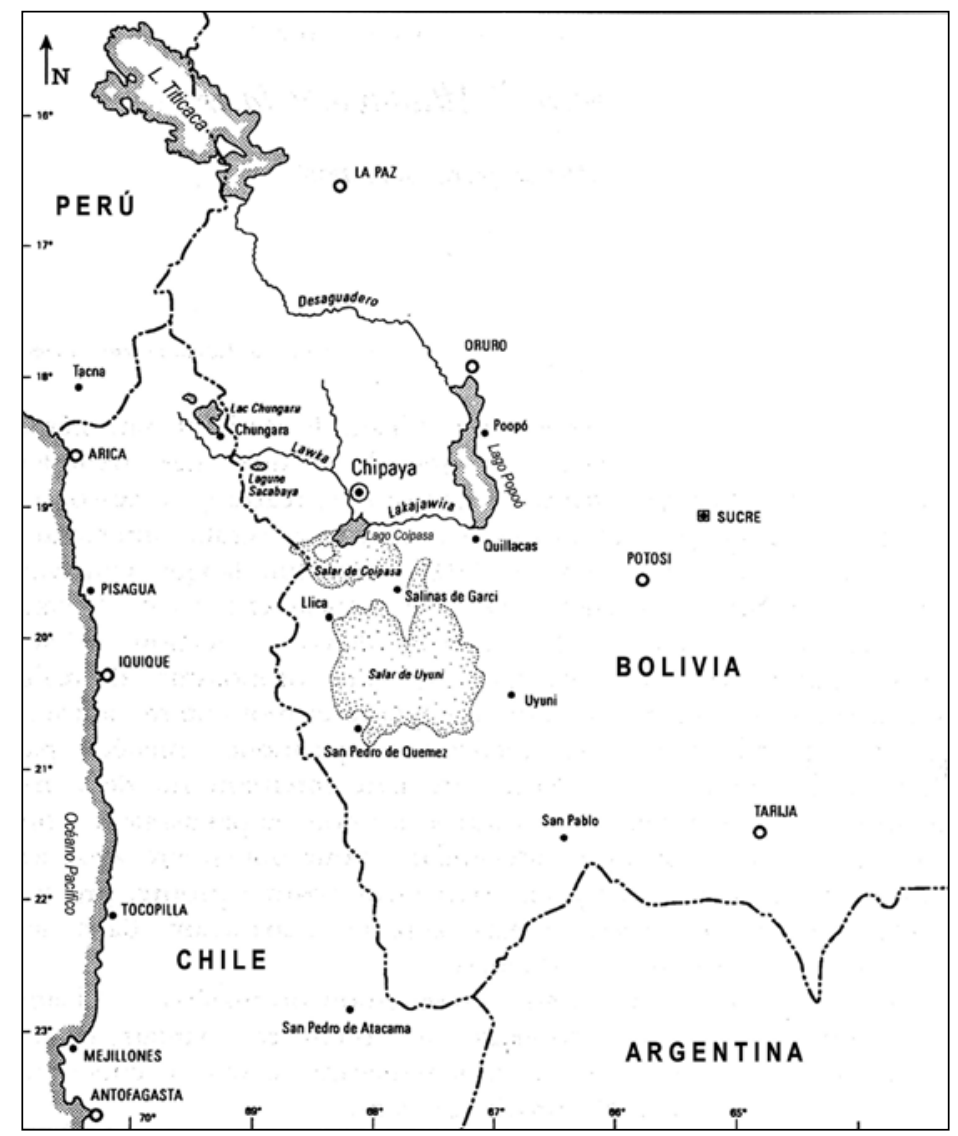

Figura 1. Ubicación de la comunidad de Chipaya.

identidades compartidas entre los pobladores antiguos de la costa y de la precordillera con estos uru chipaya de hoy. ${ }^{6}$

\section{* La percepción de un problema}

\section{Los relatos de los vientos}

El término thami designa en chipaya a todos los vientos.? Pero al interior de este nombre genérico, los chipaya dis-

6 Medina (1952), da la fecha probable de 1600 DC para la desaparición de los uru en la costa chilena.

7 No teniendo otra posibilidad, utilizo en la transcripción de los términos chipaya la ortografía aprobada en el III Congreso de Indigenistas de 1954, relativo al quechua y al aymara. La transcripción fonética de todos los sonidos chipaya realizada por Porterie-Gutiérrez no ha sido, desgraciadamente, publicada aún y solo conservo sus primeros intentos que ella consideraba muy relativos. tinguen algunos vientos específicos como los soqo, muy fríos, que soplan desde el oeste, los jarqawi, más tibios que vienen de los valles cálidos del oriente y otros vientos de menor importancia taxonómica. Entre ellos, solamente los soqo son priorizados con diferentes historias y son los únicos que alcanzan el nivel de "personajes". Así, cuando, siguiendo a los narradores, hablamos simplemente de vientos o usamos el término thami, su equivalente en chipay taku, nos estamos refiriendo siempre a los soqo, a los vientos fríos del oeste.

Sobre los soqo se cuentan dos relatos principales, que podrían leerse como historias aisladas. Sin embargo, algunos elementos, los relacionan obligándonos a considerarlos también como dos secuencias de un texto único que insinúa un pequeño ciclo mítico sobre los vientos. ${ }^{8}$

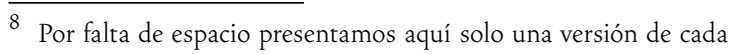




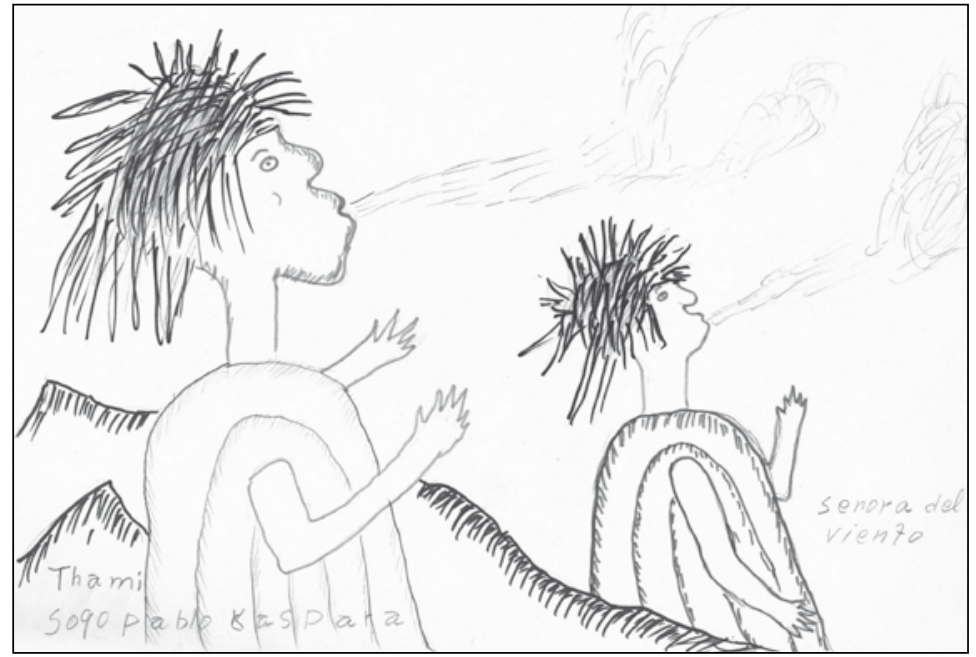

Figura 2. Los vientos. Dibujo de Martín Quispe, comunero de Chipaya.

El primer relato, El viento y las vicuñas, introduce a estos personajes, los soqo (Figura 2):

"Una persona, dice, que estaba viajando en el camino, y esa persona llegó al cerro, y una quebrada, dice, que lo miró. En un barranco, dice, que dormía una señora. Después, dice, que se acercó a la señora. 'Qué señora está durmiendo? O bien, ¿la señora está enferma?' [...] Entonces se lo saludó, se lo gritó, nada, no sentía; por nada no despertaba, dice. Entonces...'EEstará muerta?', dice que la tocó a su pecho. Y respiraba, dice. 'Entonces iestá viva!'. Dice que levante, no escuchaba por nada, dice. Esa señora, dice, que era la señora del viento. Con cabellos largos, así no peinada, dice que estaba la señora. Y así el pasajero, dice, 'Qué lo haría [a] esta señora, que por nada quiere despertar?', dice. Entonces lo revolvió su ropa, dice. Por nada, dice, no despertaba. Después levantó su pierna, dice. Y por nada no sentía. Entonces, ¿qqué haría yo?' Dice que le ha hecho una burla a la señora. Después ya, no sentía nada, por nada, dice. Entonces, terminando y abusando, el pasajero se fue por el camino. Se iba, dice, tranquilo.

Entonces el viento, su marido, dice que llegó a su señora. Después el viento a la señora bien le había visto su pierna. 'Por qué está usted tan mojada asi?' Alguien le ha hecho una burla dice que le había preguntado a su señora. La señora contestó 'no, no he encontrado ninguna persona', dice que le habia dicho. El viento se enojó y le

historia. Cuando sea necesario, sin embargo, para una mejor comprensión de cada texto, iremos haciendo alusiones a trozos de otras versiones. pegó a su señora. Y la señora que estaba llorando, y así, "ino lo sentí nada!'. Entonces el viento así, bien enojado, furioso, dice que estaba.

Después ya al lado de la quebrada y el cerro, dice que estaban comiendo [unas] vicuñas. 'Ah... estas vicuñas habrán molestado a mi señora', dice que dijo el viento. El viento se levantóy sopló y se levantó una gran polvareda, y las vicuñas, dice, que se espantaron del viento. Las vicunas corrían y corrían y el viento más fuerte. Con mucho frío, dice, las vicuñas se han desmayado. [...] Les botaba, dice, con mucha fuerza el viento, dice que les daba vueltas y vueltas [...] Y después, esa noche heló. Con el frío las vicuñas murieron. Entonces, el viento 'ya están muertas las vicuñas que han abusado de mi señora' dice... 'Voy a sacar los culos de las vicuñas', dice. Lo cortaba el viento, sacaba culos de las vicuñas, dice [...] 'Es para mi asado', dice. 'Es para mi achura.' 'Es mi ganancia', dice, 'sacar los culos, no más'.

Después, dice, que asaba, como de costumbre, el viento siempre los culos para su achura. Y después, ya comiendo el asado, el culo [...] después recién le perdonó a su señora. Después el pasajero se fue libre [...] y ellos [los vientos] 'vivían contentos..."' (M. Quispe, relato recogido por Porterie-Gutiérrez).

El segundo relato, Los vientos y el zorro, nos da a conocer nuevos rasgos de estos mismos personajes:

"El viento, en el campo, entre hartas personas estaban preparando asado. Yel zorro estaba andando. Con el olor del asado 
el zorro se acercó. 'Puedo llegar o no?', diciendo, tenía un poco de miedo. Y, por fin, el zorro se animóy [se] allegó a las personas que estaban comiendo asado [...] y los vientos eran personas de cabellos largos, chascosos, de cuellos largos, así eran las personas que eran los vientos. $Y$ le preguntó al zorro: 'PPuedes trabajar conmigo?', diciendo. El zorro le contestó: 'Puedo trabajar, puedo acompañar', dice que dijo el zorro al viento. Entonces esas personas estaban asando de puro este [...] de puro culo, y culo de los animales, y los testículos de los animales, y así puro eso, no más, dice que están los asados, con tostado de maíz plomo, le convidaron al zorro, y el zorro comió. Y ellos, dice, que hablaban. 'Hoy día es el matrimonio de Bonifacio, y, ahora, nosotros tenemos que acompañarlo', dice que hablaban los vientos, el zorro escuchaba. Y tenía un bombo [el viento] y tenía un tambor 'de coca' [especie de canasto donde se almacenan las hojas] ' $y$ un saco de llijt'a' [ceniza para precipitar la coca]. 'Ahora vamos a acompañar, vamos a ensayar un poco, vamos a dar, tocar tres veces', dice que hablaban los vientos. Y comenzó a tocar y para comenzar tocaron el bombo: 'trin, trin, trin'... Comenzó a tocar $y$ dar vuelta, una vuelta, primera vuelta, ahora segunda vuelta. $Y$ ahora tercera vuelta, dice que tocaban así, dando vueltas. $Y$ después, ya, por último, le preguntó otra vez al zorro: '¿Ahora, quieres acompañarme o quieres quedar?' dice que le había dicho el viento. Y el zorro contestó: 'Si, voy a acompañar'. Los vientos dijeron: 'Nosotros sabemos correr [...] sin tropezar, así haya tolas, así haya pajas [...]' dice que le habian dicho los vientos. El zorro contestó: 'Yo también puedo acompañar, yo sé saltar, sé dar vueltas, al otro lado, otra vuelta sé. [...] Entonces, para partir, se agarró al zorro en medio, y otra mano al otro viento y otra mano al otro viento. [...] Y comenzó ya a correr el viento; una tremenda polvareda y frío, así dice que está. [...] Yel zorro dice que estaba saltando las pajas y así. Por fin, el zorro se cansó y el viento no lo quería soltar [...] El zorro comenzó a gritar: 'Siuéltenmelo! iSuéltenmelo, voy a pagar, voy a pagar!', diciendo. El viento no escuchaba por nada. Entonces, el zorro así gritaba y se cansó y se calló; se murió el zorro. [...] Y los vientos corrían, por cerros [...]. $Y$ el zorro estaba arrastrado por el viento, estaba quedando pedazos en tolas, en piedras, así su carne..." (M. Quispe, relato recogido por Porterie-Gutiérrez).

Regresemos a la primera historia y detengámonos un instante en sus diferentes niveles de lectura, considerándola inicialmente como un texto autónomo (ver Figura 2).9

9 "Nivel" es un término operativo utilizado por la semiótica greimasiana para distinguir diferentes aproximaciones al texto. En los análisis que siguen estamos trabajando solo con el plano del contenido ("significado" de Saussure) en cuyo interior, para una

\section{Las estructuras discursivas}

El ambiente. Un paisaje alto y desolado. En la versión presentada, "una persona" (en otras versiones, "un viajero" o "un pasajero") que desde lo alto de un cerro divisa a una señora en la quebrada. Es esa acción del sujeto que "mira hacia abajo", hacia lo profundo y distante (en otras versiones se dice que mira hacia el barranco), que nos sitúa de lleno en una montaña, donde son posibles los bruscos desniveles. Más aún, alto y frío, como para ser el hábitat de las vicuñas.

Sin embargo, los chipaya habitan una pampa donde ni siquiera pequeñas colinas recortan la extensa planicie. El viajero parece haberse alejado bastante de la comunidad, internándose en el cordón occidental de los Andes, compuesto de altas cimas y valles encajonados, y que enmarca, a lo lejos, el territorio chipaya por el oeste. Entonces ¿para qué la recreación de este paisaje? Después de las primeras frases, muy generales por lo demás: "Un hombre caminaba...", o "Una persona estaba viajando...", etc.

La mención a que "miró desde el cerro hacia el barranco" permite la formación, en el que escucha, de figuras mentales precisas que van anclando la historia en una realidad más concreta. No se trata aquí de otra realidad, de un ambiente recreado y posible, pero desconocido, como ocurre a veces en una novela. Pensamos que en esta breve construcción de un escenario (innecesaria, tal vez, para el desarrollo de la acción), la alusión al "cerro" y a la "quebrada" tiene, más bien, la intención de enfrentar al oyente chipaya con una experiencia que le es familiar: los

mejor compresión del sentido, la semiótica concibe el texto como una superposición de niveles que van desde lo más concreto a lo más abstracto. El nivel más próximo -más inmediato a la captación- es llamado "estructuras discursivas", y está cargado de figuras que evocan al mundo natural, allí donde el texto plantea tiempos, personajes, ambientes y escenarios. En un segundo nivel, la semiótica aísla las grandes organizaciones sintagmáticas del texto, es decir, a la narrativa propiamente tal. Es allí donde se sitúan las acciones de uno o varios sujetos en pos de un objeto de su necesidad o deseo. Es posible vislumbrar esta relación básica (esta tensión) entre un sujeto y un objeto, como estructurada en un programa narrativo que une los distintos quehaceres y acontecimientos en los que el o los sujetos van logrando adquisiciones o sufriendo pérdidas en relación a sus metas. En un nivel más abstracto, la semiótica ubica a las "estructuras profundas", el cual corresponde a las estructuras ideológicas y sus transformaciones, que son las creadoras de una unidad de sentido de cada relato. 
caminos de alta montaña que recorre anualmente hacia la precordillera chilena, en busca de trabajo temporal. El paisaje evocado le está permitiendo una primera identificación con el "pasajero", identificación que parece ser parte del sentido de esta pequeña historia, ya que otros recursos narrativos insisten, más adelante, en crear una intimidad entre el oyente chipaya y el viajero del mito.

\section{Los personajes}

La señora del viento. Su aspecto es desgreñado, descuidado. "Su cara, pura polvareda..." dice una versión. En otra, escuchamos que "dormía la mujer con cabeza despeinada". Lo más singular, sin embargo, es su extraño sueño: "Se lo saludó, le gritó, nada no sentía, por nada no despertaba". Hasta el punto que el hombre teme que esté muerta. ¿Un sueño primitivo, sin estado de alerta, que contribuye a dibujar una imagen no cultural de la esposa del viento?

El viento. A diferencia de otros seres sagrados del panteón chipaya, el viento recibe una humanización concreta: quiere hacer uso sexual y también siente celos: "¿Por qué estás mojada?". Pero su personalidad específica se define cuando junto a su terrible fuerza (a las pobres vicuñas) "las botaba, les daba vueltas y vueltas", y demuestra su carácter ingenuo. Simplemente porque lo primero que ve son las vicuñas, las culpa, haciendo una relación atropellada de causa a efecto. Evidenciando un razonamiento inmaduro, sin complejidad. Después de castigarlas, decide darse satisfacción: "Voy a sacar los culos de las vicuñas. Es para mi asado. Es mi ganancia".

El viajero. "Era un cristiano", aclara otra versión, es decir, un ser humano real frente a la personificación figurada de los vientos. Este "cristiano" es un "vivo". Aprovecha sin hacerse mayores problemas, casi como jugando, la ocasión que se le ofrece con el sueño tan profundo de la señora. Y el mito lo deja irse sin castigo: "Y se fue tan tranquilo".

Es un personaje aparentemente transitorio ya que "sigue su camino" y desaparece de la historia. Pero es precisamente con él con quien la narración establece, a través de ciertos recursos, la relación más cercana. En muchas narraciones míticas andinas, un narrador instaurado en el texto se hace presente no solamente a través de la descripción o el comentario, sino, especialmente, de las formas estereotipadas de "dice, dicen, diciendo". Estas expresiones hacen referencia a otros narradores, impersonales, que habrían dicho (porque han visto o saben) lo que se va exponiendo en el cuento. Este mecanismo permite que el narrador guarde una cierta distancia con lo que acontece, ya que se trata de una experiencia que le es ajena. Pero vemos que cuando ocurre la escena en la que el hombre hace uso sexual de la señora del viento, el cuenta cuentos hace que el narrador se incorpore bruscamente y de un observador que era, se encarne en el sujeto. ${ }^{10}$ En muchas versiones, el cuenta cuentos se ayuda de los ruidos “iwa, wa!", de entonaciones y gestos, para efectuar esta transición, al mismo tiempo que la descripción aumenta la densidad de sus detalles. El "pasajero" se nos vuelve así de carne y hueso, y podemos seguir sus vacilaciones, sus procesos: "Entonces lo revolvió su ropa, después, levantó su pierna. Entonces, “iqué le haría yo?”.

Estos recursos de la narración traen al personaje a un primer plano. Lo que nos interesa aquí, sin embargo, no son los delicados mecanismos de los que se vale el texto para crear este efecto de "iconicidad", sino la empatía que levanta en el oyente: puede recibir la experiencia del viajero mítico como suya propia (y utilizarla, luego, en contra del viento a lo largo de una ceremonia). ${ }^{11}$

Las vicuñas. Además de ser las víctimas inocentes, su presencia ayuda a recrear ese ambiente solitario y de altura. Diríamos que las vicuñas llevan siempre el tema de las alturas frías. Contribuyen, también, a perfilar el carácter del viento: se ensaña sin piedad, con ellas, las más débiles.

\section{La temporalidad}

La narración sitúa los hechos en un pasado, pero, ¿̇cuán lejano es ese pasado? No podemos situar la "antigüedad" - si es que ello fuese posible- de aquel día en que un hombre dejó una impronta sobre los soqo.

\footnotetext{
${ }^{10}$ En los diferentes relatos míticos andinos es posible distinguir siempre un narrador, alguien que, ubicado en el interior del texto mismo, va describiendo o comentando los sucesos. Pero el que en la vida real relata esa historia, hace también sus aportes interpretativos: entonaciones, gestos, pausas, ruidos, risas, etc., que forman, igualmente, parte del sentido. Para diferenciarlo del narrador que viene incorporado en el texto, lo llamamos "cuenta cuentos".

${ }^{11}$ Iconicidad: Ilusión fuerte de realidad creada por diversos procedimientos discursivos, entre ellos, una sobredeterminación de los rasgos figurativos.
} 


\section{Las estructuras narrativas}

El viento ha sido engañado por el hombre, aunque no lo percibe. Ese pasajero le ha quitado un "bien", su orgullo de macho, y sintiéndose ofendido, busca una reparación. Como un niño que ha perdido un juguete y se contenta con otro, reemplazará esta herida asegurando su terrible fuerza y sacando los culos de las vicuñas. Luego "vive muy contento", aunque a raíz de la acción secreta del hombre ha quedado condicionado a un nuevo hábito alimentario. Esto se reafirma, en otras versiones, con frases como: "Siempre sus nalgas quiere el viento".

\section{Las transformaciones a nivel profundo}

Casi sin pensarlo, el pasajero se arriesga y "hace uso" de la esposa del viento. Está jugando con fuego, ya que el viento es muchísimo más fuerte y si lo sorprendiera... Sale, sin embargo, victorioso de su hazaña y puede seguir "tranquilo su camino". Con la acción del hombre, una doble transformación parece ocurrir en el relato. En primer lugar, la del viento: al ofrecerse a sí mismo un banquete de nalgas (que vemos en plena acción en el mito del zorro), el viento satisface no solo su hambre, sino que cada vez compensa también aquel orgullo herido. Así, adquiere un vicio, una dependencia (lo veremos comiendo su "asado", su achura, en idioma nativo, no solamente en otros relatos sino igualmente en las ceremonias que se le dedican). Y esta dependencia dará a los chipaya un principio de dominio sobre el viento: ofreciéndole aquello que le causa tanto placer pueden atraerlo, sea para "adorarlo", cuando es necesario que sople, o "amarrarlo" cuando está causando daño a las siembras.

En segundo lugar, es posible también percibir un cambio que podríamos llamar extratextual. El cuenta cuentos está encarnando al "enunciador" (al sujeto que enuncia la historia, el autor, por decirlo así). Este enunciador es un sujeto anónimo y colectivo, enraizado en la cultura. Pero toda historia es siempre enunciada para que otro sujeto, al escucharla, la decodifique y la haga suya. Así, este oyente activo va reconstruyendo ahora los hechos en su propio intelecto. El oyente, en la medida en que se le permita identificarse con el viajero, se convierte en otro sujeto que también experimenta una transformación, pues recibe, a través de la historia, un "saber", un conocimiento sobre la mente ingenua del viento. Si un día, en un camino, arriesgándose, un chipaya cualquiera lo hizo, es posible, entonces, burlar al viento y contentarlo después. Sujeto de una semiótica viva, el oyente del cuento sufre, a su vez, un cambio fundamental que se refiere a su competencia en el dominio ecológico.

El mito parece marcar el inicio de una semidomesticación de los soqo, que quedan, en cierto modo, sometidos a la voluntad de los hombres. Efectivamente, antes, cuando aún había sukachiri del viento (encargados rituales de éste), ellos lo "arreaban" por los caminos, icomo si se tratase de ganado!, premunidos de una honda. Esta honda estaba hecha de skaranta kawñi (hilo torcido a la izquierda), de colores "manchados" (característicos del viento, como veremos más adelante) y, a veces, con pelos de perro.

¿Qué sucede con los Los vientos y el zorro? En una primera lectura puede ser considerado como un cuento más de los muchos cuentos aymara en que el zorro, por su carácter jactancioso, se mete en problemas y recibe un castigo. En todas esas historias, el protagonista es el zorro y los otros personajes participan, más bien, como agentes de su destrucción. En este relato, sin embargo, varios elementos hacen pensar que los chipaya están efectuando una inversión, y que ahora son los vientos los protagonistas. Notemos cuántos detalles se nos entregan de su personalidad: que son músicos que tocan de una manera específica, que mascan coca acompañada incluso de llijt'a, que tienen un pariente que se casa, etc., mientras que del zorro nada aprendemos, salvo lo que se reitera de otros cuentos andinos. Pero es, sobre todo, una referencia la que nos impide leer la historia desde el punto de vista del zorro: los vientos están asando "puro culo, culo de animales y los testículos", o, como lo explicitan otras versiones: "iEstán asando mucho culo, mucho!", "iGordos, lindos culos!".

¿Cómo no relacionar este hecho con la afición por las nalgas que vimos iniciarse en el primer relato? El hábito del viento por alimentarse de este lugar específico del cuerpo de sus víctimas, aparece en el segundo relato en pleno desarrollo. Se trata ahora de verdaderos festines golosos en que los soqo se regalan con culos, penes, vulvas, anos. Es evidente que el segundo relato se está refiriendo al primero y, efectivamente, El viento y las vicuñas me fue contado cuando, después de haber escuchado Los 
vientos y el zorro, pregunté intrigada por qué los vientos comen culos, penes y vulvas. La respuesta fue el relato de El viento y las vicuñas, como si este relato fuese toda la explicación posible. El viento y el zorro se presenta, así, como la consecuencia mítica del primero, estableciendo en un orden lógico, un antes y un después que permiten ordenar los dos relatos como dos secuencias. Se trata de una relación a nivel superficial, en la temporalidad de los relatos. Esto permite preguntarse, sin embargo, si hay una relación más profunda entre ambas historias.

\section{Las estructuras discursivas de Los vientos y el zorro}

Vemos reiterarse, en este nivel, algunos elementos del primer relato, como el ambiente en el que ocurren los sucesos y la humanización de los vientos.

El paisaje. Como en el caso anterior, el narrador no se detiene a describir un escenario concreto. La aprehensión de los lugares surge de la acción de los personajes. Se insiste, una y otra vez, en todas las diferentes versiones de esta segunda historia, en la presencia de vegetación de planicies muy altas. Los vientos saben correr: "Así haya tolas [arbusto del altiplano que se usa como leña y que solo crece sobre 3500 m.snm], así haya pajas...". Y el zorro: "estaba pasando por un pajonal...", o "saltaba la paja, saltaba la leña...", y al ser destruido va quedando: "pedazos en pedazos en tolas, en piedras...".

A esta imagen se agrega la presencia, un poco más desdibujada ahora, de una topografía de quebrada: "Y los vientos corrían por cerros", "al subir el cerro, el zorro se cansó..." "y después [de matar al zorro] el viento descansó en un valle...".

Breves frases, pero que permiten visualizar las escenas como sucediendo en un ambiente particular. ¿Para qué esa insistencia en mencionar tolas, piedras, pajas? Como en la historia anterior, no podemos dejar de percibir un recurso literario para crear una ilusión de realidad que torna ambigua la evidente ficción del mito. Esta ambigüedad, este juego entre la fantasía y la experiencia de lo real forma parte, tal vez, en ambos relatos del goce estético con que son narrados, pero, al mismo tiempo, esta reiteración, en la rígida economía expresiva de los mitos, levanta una inquietud: ¿hay un segundo sentido, codificado en el paisaje, que aún no podemos alcanzar?

\section{Los personajes}

La humanización. En muchas versiones de Los vientos y el zorro se utilizan los términos personas, hombres o gente para referirse a ellos, aunque agregando, a veces, "eran como...".

Esta humanización va acompañada, como en la primera historia, de un aspecto salvaje en la apariencia de los soqo: evidentemente no se peinan, son "chascosos". Y tal como la señora de la primera historia no sintió al hombre "que entró en ella", los vientos, ahora, son insensibles a los gritos del zorro: “iAndá con calma, andá con calma! iEspera un poco!, iay! El viento no escuchó". Y en otra versión: "Ya, isuéltenme, voy al servicio! El viento no escuchó su reclamo".

Notamos que los vientos tienen necesidades físicas como cualquier mortal, y que no solo almuerzan para tener fuerzas antes de correr, sino que descansan y junto con descansar, coquean (mascan coca) ie incluso hacen uso de la llijt'a! (ceniza que precipita la coca). Esta humanizacion va acompañada de ciertos rasgos mucho más precisos como:

Una cierta socialización. A pesar de su apariencia acultural, los vientos responden a solidaridades tradicionales. En todas las variantes, un personaje llamado Bonifacio -cuando el relato es en castellano- y Munejasu -cuando es en chipay taku-, se está casando. De Bonifacio se dice que es un pariente de los vientos. Los soqo tienen, pues, familia, y sienten obligaciones hacia ella: deciden acompañar a Bonifacio en su matrimonio y siempre demuestran apuro por llegar a la fiesta. Aportan, al parecer, con la orquesta, preocupándose por cumplir correctamente con esa obligación amistosa: "El pariente se casa, ahora nosotros tenemos que acompañar', dijeron. Después, harto trin, trin, trin tocaron. 'Bonifacio nos ha invitado a un matrimonio. Ahí tenemos que alcanzar urgente'”.

Es justamente en relación a esta obligación, que los vientos establecen una especie de mink'a (intercambio de comida por trabajo) con el zorro. Reciben su asado a cambio de una tarea específica: “'iPuedes trabajar conmigo?', diciendo. El zorro le contestó: 'Puedo trabajar, puedo acompañar'".

Desde el momento en que come, según la costumbre andina, adquiere un compromiso. Está tan consciente de este pacto que, cuando ya no resiste la carrera, en muchas ver- 
siones grita: “iSoltáme, soltáme, voy a pagar, voy a pagar!" Pero, como sabemos, "el viento no escuchó por nada."

La musicalidad. Aprendemos en esta segunda historia que los soqo son músicos, y al menos, en lo que respecta a la percusión ison buenos músicos!, ya que en varias versiones se dice: "iEl bombo sonando fuerte, lindo!".

Resulta curioso, sin embargo, el hecho de que no son músicos al natural -simples vientos que soplan- sino que, como cualquier hombre, deben ensayar antes de tocar: "Ahora, vamos a ensayar un poco, vamos a dar [al bombo], a tocar tres veces". E incluso, el "canto" o melodía que tocan, parece estructurado: "Ya, tocaron. Un canto tocaron. Ya, primer comienzo, segundo comienzo, tercer comienzo, tres veces dieron vueltas". Como verdaderos músicos, se "arman" su bolo de coca, para realizar bien su trabajo: "Después de un largo rato, el viento se armó su coca. Cualquier llijt’a masticó". En otra versión, incluso le ofrece al zorro: "¿Vas a acompañarme? Entonces ármate un poco de coca”. ¿Para qué acercar tanto los vientos a los hombres?

Por último, hay en esta segunda historia, un pequeño dato que pudiera pasar inadvertido, y que sin embargo, insinúa que los soqo se están integrando a una estructura mayor con otras deidades o potencias sagradas: es la lógica sensible que acompaña a la creación imaginaria de los soqo. Se plantea para ellos, en muchas versiones de El viento y el zorro, un lenguaje paralelo de colores y gestos, que se enriquecerá en las ceremonias que les son dedicadas, con olores y sabores que les pertenecen. Éstas se caracterizan por:

Un cromatismo particular. Las diferentes versiones insisten en describir una preferencia por ciertas tonalidades, pues se visten con trajes a veces "medio blanco", otras "con trajes plomos de lanas plomas". El maíz tostado con que acompañan su asado es también plomo en una versión y willka paru en otras. Paru es una combinación de manchas muy pequeñas de diferentes grises, es decir, una apariencia de definiciones sutilmente imprecisas. Un narrador agrega, que comen penes y anos de "animales de color t'ejllu". El t'ejllu, como el paru, es también un color formado de pequeñísimas dosis de blanco y negro, o gris oscuro. La tonalidad de los soqo es, pues, opaca, sin colores puros o vehementes, sin contrastes, apareciendo de lejos como indefinida.
Un desplazamiento en curvas. Un detalle casi imperceptible en el primer relato, pero que se repite con insistencia en el segundo, es que los soqo son pensados como siguiendo caminos que dan vueltas, o tal vez, en espiral: "[Dicen al zorro] 'Vamos a comenzar la primera vuelta', y luego comen para dar la segunda vuelta". Se podría pensar que están repitiendo el movimiento de las "tropas" (conjuntos de músicos autóctonos) que tocan girando en círculo. Pero, también, a las pobres vicuñas: "les daba vueltas y vueltas", o "las vicuñas arreando dando vueltas al otro lado", etc.

Es interesante la precisión que agregan algunos narradores, al señalar que estas vueltas se realizan siempre por el lado izquierdo: "Así, agarrando al zorro, iban dando vueltas por la izquierda", o "iban dando vueltas por el lado izquierdo".

Una lógica sensible presupone siempre un pequeño sistema taxonómico que organiza categorías concretas en oposiciones y semejanzas. Los soqo, pues, no pueden ser los únicos que participan de un lenguaje sensible. Efectivamente, si a los vientos se les atribuye lo manchado o impreciso en el color, los mallku o dioses tutelares, reciben como ofrenda maíz blanco mientras los "Caballeros" (santos católicos) son agasajados con maíz rojo oscuro, es decir, ambos, por oposición a los soqo, con colores enteros y bien definidos. La lógica sensible presente en la segunda historia está sugiriendo, de ese modo, que los soqo, aunque sea humildemente, participan de una organización semántica en la que toman posición en relación a otras deidades.

\section{Las transformaciones fundamentales}

¿Qué sucede en este segundo relato? En el primero, el hombre, sin quererlo, fue el sujeto de la transformación de los vientos. Vemos ahora, que son los vientos los sujetos de la transformación del zorro. Pero, ¿qué les ocurre a los vientos en sí mismos? En esta historia, parecen hacer solamente lo que hacen siempre, comer y correr. Si ellos son los protagonistas, sin embargo, deberían participar en una estructura narrativa donde lo esencial es la relación conflictiva de un sujeto con un objeto de su deseo o necesidad. Ni siquiera es evidente que sea por enojo que despedazan al zorro. Simplemente van a donde tienen que ir, en este caso el matrimonio de Bonifacio, sin que nada pueda doblegar su determinación. Corren y corren, olvidados de todo, sin escuchar, sin sentir, y la consecuencia de esa potencia e insensibilidad, es el desgarramiento del 
zorro. Es difícil definir la carencia que buscan compensar a lo largo de este segundo relato para que éste tenga, desde el punto de vista de los vientos, otro interés que no sea el de la descripción de los personajes.

Sin embargo, si consideramos El viento y las vicuñas y Los vientos y el zorro, como un solo mito formado por dos episodios, se pone de manifiesto una única estructura narrativa que, sacando a luz el sentido, da cuenta de los procesos sufridos por los soqo.

Designemos como S1 al sujeto "vientos". ¿Qué sucede cuando el hombre abusa de su mujer en la primera historia? El viento es despojado de algo, herido en su orgullo, en su vanidad. Podemos considerar que ese orgullo es lo que la semiótica llama un "objeto de valor", algo que el sujeto, en este caso, el viento, necesita o desea para estar en equilibrio. Designemos a ese objeto "orgullo" como O1. ${ }^{12}$ Después de la acción del pasajero, el viento está sin su orgullo, lo que podemos expresar, siguiendo una convención semiótica, como: $\mathrm{S}_{1}$ u $\mathrm{O}_{1}$ (siendo "u" un signo convencional de ausencia o disjunción).

Pero al castigar a las vicuñas y sacarles las nalgas para preparar su asado, Si encuentra una nueva compensación que podríamos considerar como un placer de venganza que arrastra consigo un placer de gula. De ahí, entonces, el Si queda ligado a ese nuevo objeto de valor que anotaremos como $\mathrm{O}_{2}$ :

S1 n O2, una cierta compensación ligada al hábito alimentario (siendo ahora " $\mathrm{n}$ " un signo de conjunción).

Y, sin embargo, su vanidad herida no ha sido restaurada aún. De modo que: Si n O2, pero u O1.

El segundo relato, en cambio, ensalza a los soqo. Si el zorro ha creído poder burlarse de ellos, son los vientos ahora los que se burlan de él. Aparecen invencibles y poderosos, y ni ruegos ni razones pueden con ellos. Su orgullo y vanidad están otra vez en alto: S1 n O1 pero, también, Sı n Oz.

\footnotetext{
${ }^{12}$ Numerosos trabajos que abordan la narrativa desde el punto de vista de la Escuela de Semiótica de París, utilizan este tipo de esquema para dar cuenta de las transformaciones fundamentales que suceden al interior de un texto. Un desarrollo explícito de este tipo de anotación se puede ver resumido en el Programme Narratif de Greimas y Courtés (1986: 177).
}

Al mismo tiempo que el oyente decodifica el mito que le van narrando, junto con conocer en la primera historia el carácter ingenuo del viento y la hazaña de un viajero, recibe ahora un saber sobre los aspectos temibles de los soqo: su fuerza destructiva e indómita. Si consideramos los dos relatos como formando parte de un mismo mito mental, este parece estar organizado por una estructura de base que podríamos plantear como dos términos contrarios: sometimiento vs. independencia. Posibilidad de dominar a los soqo, e imposibilidad de hacerlo. Los vientos del oeste parecen situarse en el término complejo de esta categoría de la "domesticación", ocupando una posición compleja.

\section{Soqo: Sometimiento vs. independencia}

Es decir, son y no son controlables por el hombre. Vemos así que el tema de estas historias, aparentemente ingenuas, es nada menos que el tema del control ecológico. La unidad de los dos relatos como el sentido que vamos desprendiendo de ellos, se hacen más evidentes en la ceremonia de "amarrar al viento", donde los chipaya -autores y receptores de este doble mito- hacen un uso práctico de él.

\section{La ceremonia de "amarrar" al viento}

Resumimos, a grandes rasgos, esta ceremonia, deteniéndonos solo en aquello que va sugiriendo una referencia mutua entre los textos. Años atrás, cuando este rito tenía toda su vigencia, debía ser convocado por los sukachiri del viento (sacerdotes o encargados rituales de los soqo) de las dos mitades de la comunidad. Pero en 1982, este cargo ya no tenía titular: el último sukachiri del viento había muerto y, con el debilitamiento de la religión tradicional, no había sido reemplazado por otro.

A fines de octubre, sobrevino en Chipaya una verdadera tormenta de viento. Durante seis días seguidos los soqo soplaron con inusitada fuerza levantando enormes nubes de polvo. Amenazaban hacer volar las pequeñas semillas de quinoa recién sembradas que se depositan casi a ras del suelo. Era el momento, también, en que las chacras necesitaban de las lluvias que vienen del oriente, pero los vientos del oeste barrían las nubes. Ante estos peligros, los dos kamayoj de las chacras de Aransaya (los encargados de la vigilancia de los sembradíos de la mitad de arriba) decidieron revivir una ceremonia ya casi caída en desuso, para intentar "capturar" a los soqo. 
La ceremonia tiene un carácter privado. Se determina de un momento a otro y se prepara rápidamente, al atardecer, y en silencio, convocando tan solo a unas pocas personas cercanas a los oficiantes: la intención es sorprender a los soqo antes de que se den cuenta de aquello que se trama contra ellos.

Los preliminares. La reunión se realizó en el templo de San Santiago, una pequeña capilla del ayllu que aún queda en pie, a pesar del ingreso al pueblo de las nuevas religiones. ${ }^{13}$ El putira (encargado y conocedor de las tradiciones, que cuida el templo), un hombre muy anciano, dirigió el ritual. Fue el primero en llegar para confeccionar la vela de Santiago, un mechero hecho de grasa y algodón, que puso junto a una mesa frente al altar. Fue la única luz que nos alumbró durante la noche. Luego el putira acogió a uno de los kamayoj de las chacras (encargado anual de cuidarlas), que ofició de ayudante. Juntos encendieron incienso en honor del santo y sacaron la pitaxa, un cofre con "tesoros" que se guarda en el altar, colocándolo sobre una banqueta.

La capilla estaba ya semi abandonada. Por un agujero del techo era posible divisar el cielo estrellado. En el interior todo estaba lleno de polvo. Las flores del altar, secas desde hacía mucho; los adornos de papel, desteñidos y rotos. El viento ululaba afuera de manera impresionante.

Poco a poco, fueron llegando los demás asistentes, un grupo muy pequeño. Primero se hincaban un momento frente a San Santiago, solicitándole su permiso y luego ocupaban sus lugares: los hombres, en el poyo (asiento en obra) del costado sur del templo, cuya puerta mira al este, y las mujeres en el suelo, frente a ellos. Todos hablaban en voz muy baja, e incluso los niños, contagiados de ese ambiente oscuro y silencioso, correteaban a espaldas de sus madres sin hacer ruido. Se tenía la impresión de un acto clandestino.

Un voluntario que hacía de "empleado" trajo un cordero que acostó junto a la puerta abierta. Solo, entonces, el putira y su ayudante abrieron el cofre e inspeccionaron cuidadosamente su contenido como si nunca lo hubiesen visto. Sacaron primero una inkuña que no tenía ningún diseño (siendo un tejido ritual utilizado para pedir lluvia), y que

${ }^{13}$ Diversas sectas evangélicas han ido imponiendo su influencia por sobre concepciones o rituales de la religión católica o de los cultos tradicionales. aquí es llamada mush. La extendieron en la mesa junto al mechero. El putira desató el cordón que estaba amarrando la boca de una talega y ordenó, delicadamente, las bolas que se guardan en su interior: cuatro metales casi redondos de diferentes colores, uno plomo, uno rojizo, uno oscuro considerado "negro" y uno blancuzco, llamados wala (proyectiles del rayo). Hizo estos movimientos sin sacar las piedras ya que no deben ser expuestas a los ojos de otros. Hasta aquí, todo estaba dirigido a los santos, y especialmente a Tata (San) Santiago, que junto a San Felipe, montados en sus caballitos, miraban desde el altar. Ellos son los "dueños" de esa capilla (ya que son los santos los que gobiernan la lluvia y el rayo), y el incienso, la mush inkuña y las wala, son objetos de su ámbito sagrado.

Pero, en ese momento, otro oficiante encendió el copal. Si el incienso estaba ahí para pedir permiso a San Santiago, el perfume del copal solicitaba ahora autorización de los paris angila. Los paris angila son cuatro champi (grandes prendedores antiguos), de plata, rescatados de enterratorios de los antepasados. ${ }^{14}$ El par más grande es llamado específicamente paris angila (par de ángeles), mientras el par más pequeño - que también es ángel - es llamado winchani. Estos paris angila que se conservaban también antes en otras capillas de ayllu, juegan el rol de intercomunicadores con fuerzas sagradas. El putira los alzó del cofre y se colocó el par más grande en su chiqi (un tipo especial de chuspa o bolsa para la coca, que entrevera tramas de vellón sin hilar que, al quedar flotando, dan la impresión de una piel animal), mientras el kamayoj de la chacra hacía lo mismo con los winchani. Sacaron del cofre, por último, dos campanitas, una que representa a San Santiago y la otra a San Felipe, y se las pusieron en las bolsas de coca, junto a los paris angila. Con el permiso de los paris angila se pudo hacer la willancha (sacrificio ritual), llevándose el cordero para degollarlo. Al revés de los otros sacrificios que se realizan en Chipaya hacia el este y con la mano derecha, esta willancha se realizó en la parte posterior del templo,

\footnotetext{
${ }^{14}$ En los trabajos agrícolas o de regadío, los chipaya recuperaron muchas veces objetos de plata antiguos que llamaron champi. Estos objetos no corresponden a los champi precolombinos (mazas o cachiporras) sino a los prendedores usados por las mujeres para sostener su manta (más conocidos como tupu): tienen la forma de un círculo de plata labrada con una larga punta aguzada. Son considerados ángeles porque se les asigna el papel de intermediarios, de intercomunicadores con otras fuerzas sagradas. Desempeñan, además, el papel de samiri de los seres humanos, es decir, de agentes de su suerte y procreación.
} 
hacia el oeste y con la mano izquierda: representaba, así, una ofrenda específica para los soqo. La sangre fue derramada hacia el oeste y hacia el sur, lugares desde donde se supone que provienen los vientos, invocando: "ikamana de los soqo!" (lugares sagrados donde los vientos nacen o descansan). También las señoras que se encargaron de la cocina, prepararon el cordero con su mano izquierda.

Primera parte: Atraer a los soqo. Solo cuando los hombres regresaron de la willancha, empezó realmente la ceremonia. Circularon los vasitos con alcohol, los cigarrillos y los intercambios de chuspa. Con un gesto, los oficiantes recordaban que todo debía ser hecho con la izquierda. El putira, con voz de ruego y muy tierna, se dirigió a los soqo por sus nombres rituales: “iGaspara!... iWaltasara!... iQalasaya!...", agregando frases cariñosas: "Aquí tienes tu invitación, tu phit" (llijt'a o ceniza para mascar la coca). Los demás lo siguieron, derramando un poco de alcohol e implorando: "iSoqo Paulo!... iKaspara!... iMelchora!”. Los nombres variaban, pero siempre eran tres, uno por cada ánimo del viento, incluyendo, a menudo, los nombres de los "reyes magos". ${ }^{15}$

La conversación se hizo animada, aunque siempre en tono muy bajo, lo que contrastaba con el estado de placer y excitación que demostraban los asistentes. El kamayoj salía constantemente a renovar la ofrenda de coca y llijt'a para los vientos, que dejaba, hacia el oeste, en la parte posterior del templo. Uno de los asistentes empezó a hilar vellones de oveja hacia la izquierda (skaranta kawñi) para hacer cordones, mientras otros tres se preocuparon de inflar, una y otra vez, tres bolsas de nylon para asegurarse de que no estuvieran rotas. Todo con gran calma.

Y fue entonces, cuando las mujeres iniciaron la narración de una historia. iSe trataba nada menos que de Los vientosy el zorro! No la contaban fluidamente, sino que entre sonrisas, con placer y entusiasmo, dejaban caer pequeñas frases como "Dicen que olía a asado, rico asado... Y el zorro se acercó". Las demás mujeres sofocaban su risa. Y otra agregaba, entonces, una breve frase más: “iConmigo puedes

\footnotetext{
${ }^{15}$ En la comunidad aymara de Isluga, colindante con Chipaya, los nombres de los "reyes magos" son reservados para las varas de mando del los mallku (caciques) de turno. Estas varas llevan el nombre genérico de Santo Rey. La aplicación de estos nombres a los soqo, en un contexto ritual, sugiere que los vientos del oeste tienen el prestigio de "reyes", a pesar del lamentable suceso del hombre con la señora del viento.
}

correr?, le dijo el viento...". Y todas volvían a reír como si les causara una enorme gracia. Era evidente que tanto el tono juguetón de las mujeres, como el ligeramente irónico que adoptaron los hombres, era una actuación que formaba parte de la eficacia ritual. Los hombres interrumpían, a veces, los relatos de las señoras, agregando algún detalle muy concreto, que acompañaban con un gesto para darle todo su efecto de veracidad: "iSangre, sangre dice que quedó, no más, en las manos de los soqo!", y luego regresaban a sus invocaciones llorosas: “iThamis!". Naturalmente, todos conocían el cuento y no hacía falta relatarlo, sino simplemente, recordarlo para placer de los soqo que, detrás de los muros, estarían escuchando. De este modo, la historia funcionó como una ofrenda más a los vientos, como la coca, como el phit, o como el asado que se les ofrecería un poco más tarde.

Segunda parte: Capturar y hacerse perdonar. El putira interrumpió la secuencia. Levantando una mano dijo: "iYa!". Los hombres se miraron y, poniéndose de pie, salieron calmadamente de la iglesia. El putira y el kamayoj se quedaron adentro, junto a las mujeres, pero ahora sin hablar, escuchando con gran atención, cómo, a la luz de la luna, los hombres corrían por el lado sur de la capilla, contra el viento, riendo y gritando, tratando de que el aire llenase las bolsas de nylon que habían preparado. Una vez llenas, las iban amarrando con el skaranta kawñi. Regresaron al templo para detenerse, excitados y sonrientes, frente al altar. El putira alzó, entonces, una gran cruz de madera de palma, sosteniéndola medio inclinada ante las tres bolsas que contenían al thami. Y luego, amarrando las tres bolsas a la cruz, la dejó de pie, en la mesa junto al altar. Todos se hincaron para rezar, y siguieron así hasta el momento en que el putira, poniéndose de pie, inició el saludo tradicional: "iQué sea en buena hora!". Los asistentes se abrazaron.

La conversación se volvió brillante. Circularon más rápidamente las copitas con alcohol. Empezó un nuevo estilo de ch'alta (palabras que se pronuncian al ofrendar unas gotas de licor). Dirigiéndose, muy cariñosamente a los vientos atrapados en las bolsas, se les decía "iYa no vas a seguir corriendo! iAquí, vas a estar bien, tranquilo, no más!" O, refiriéndose a las ofrendas puestas en el interior de las bolsas: "Todo tienes, tu coca, tu phits...".

Se dice que el viento escucha atento y callado. En el "drama" a interpretar, los hombres se hacían los humildes, ocultando el orgullo de haber hecho caer a los soqo, por in- 
genuos, en la trampa tendida contra ellos. Pero, al mismo tiempo, dejaban traslucir ese placer íntimo del actor: conociendo las reglas del juego, cada uno desplegaba la situación con creatividad, con goce, con autoridad de entendido. Sin embargo, había algo de auténtico en ese comportamiento ritual: una cierta simpatía y ternura por los soqo.

Continuando aún los gestos con la mano izquierda, se invocó luego a las altas cumbres occidentales (especialmente aquellas del lado chileno) y a las amplias pampas, rogándoles atajar al viento: "Isluga volcana, Isluga mallku [dios tutelar del cerro] ino vas a dejar pasar!". "Sojalla pampa iay pampa de Sojalla!" (pampa en la subida a Isluga). Los asistentes parecían inspirarse tratando de recordar los precisos lugares por los que se supone que viene el viento: "iParis qota!..." (en el sendero de llamas hacia Camiña), “iWari Palasa!” (en este mismo sendero), "Arin T'ika, Pukin T'ika ivas a atajar!" (dos grandes cerros hacia el salar de Suriri, venerados también por los aymara). Se hacía evidente que el pensamiento mítico obligaba a los soqo a recorrer, en sentido inverso, los mismos senderos milenarios utilizados por los chipaya y aymara, en su descenso hacia la costa, y que hombres y vientos compartían los mismos lugares sagrados. Al mismo tiempo que un paisaje, todavía cercano, se iba dibujando en la mente de los que han caminado por esos lados.

Una mujer entró trayendo un plato con el culo del cordero, apenas sancochado en las brasas, y maíz tostado, que dejó debajo de las bolsas de los vientos. Las invocaciones se hicieron más exaltadas y tomaron los caminos del descenso hacia el desierto. "iJanq'o apacheta, vas a atajar!". Pero Janq'o apacheta es ahora apenas un montón de piedras que saludan los caminantes al pasar, no ya un alto cerro con prestigio que todos divisan de lejos (incluso el viento) o una amplia pampa. ¿Por qué un lugar tan preciso era relacionado con el paso de los soqo? No era el único: Tapa apacheta, luego alrededores muy concretos de Chiapa, pueblo situado ya en plena precordillera: Wichuta, Kayku, Jachura, Columayu. En ese momento, un asistente empezó a explicar que los vientos nacían en el mar. Pero en un corredor (que diseñaba con un gesto de sus manos) "un poco al sur de Iquique". ${ }^{17}$

\footnotetext{
${ }^{16}$ El volcán Isluga está junto al ayllu del mismo nombre, ubicado hoy en territorio chileno.

${ }^{17}$ Iquique: Ciudad y puerto chileno que mira al océano Pacífico. Entre los territorios chipaya y el mar, se levantan las altas cumbres occidentales de la cordillera de los Andes, luego la "precordillera"
}

Inmediatamente, le corearon con invocaciones: "ilquique puju! (vertiente de Iquique), imar de Iquique!”, “imar de Camiña, no dejes nacer, no dejes formar!”. Se quitaban la palabra para contar cómo, desde el mar, suben los soqo, entre vueltas y remolinos, recordando los pequeños lugares por donde pasan: la precordillera de Chile se configuraba así, tan vivamente a los ojos, a través de detalles como un montón de piedras, una laguna, que era imposible no preguntarse porqué y para qué la evocación tan precisa de ese paisaje. Se escuchaban unos a otros, como si este recorrido les causara asombro: “iAhhh!...”, aprobando con murmullos y sonriendo ante la enorme potencia de los soqo, que el narrador de turno imitaba con ruidos.

De pronto, todos se quedaron en silencio, escuchando. Afuera el viento se había detenido. Esperaron inmóviles. Después de una pausa, el kamayoj exclamó: "iHemos vencido!". Las mujeres empezaron a reír abiertamente. $Y$ aunque, momentos después, el viento regresó con fuerza, siguieron repitiendo: “iEl viento está vencido!”. Dirigiéndose a las bolsas, les decían con picardía: "iAhí te quedarás tranquilo!". Sobrevino una segunda pausa de silencio en la que cada uno estaba atento a los ruidos fuera del templo: el viento parecía haberse ido definitivamente. Aprovechando ese momento, el kamayoj dio por terminada la lucha contra el viento e inició otra fase de la ceremonia.

Tercera parte: El llamado a las otras deidades. El kamayoj dijo: "Ahora vamos a convidar a los Caballeros". Agregando con énfasis: "Ahora, con la derecha". Los Caballeros son los cuatro santos principales que se veneraban en Chipaya: San Santiago y San Felipe, en Aransaya, San Jerónimo y Yunguyo, en Manasaya. Se los considera como gobernantes del clima que viene desde el oriente, de la lluvia, y del rayo. Estando los soqo cautivos, los Caballeros podían ahora hacer avanzar las nubes húmedas. Los hombres comenzaron a invocarlos por sus nombres, mientras las mujeres iniciaron un segundo relato: el de la llegada de los Santos Caballeros al pueblo. Al igual que en la historia de Los vientos y el zorro, solo dejaban caer frases aisladas, sonriendo siempre, como si los sucesos de este nuevo relato les causaran tanta gracia como los del relato anterior. El placer consistía, más que en reproducir grandes acontecimientos, en revivir un pequeño detalle, en hacerlo aparecer como real con la

o contrafuertes descendentes", en seguida el desierto, luego la poco elevada cordillera de la Costa, y por fin, el litoral. A todo este paisaje se refieren los recorridos de los vientos. 
ayuda de ruidos y de gestos. "Era de noche, dice... No había luna... Durmiendo... Silencio... iChaaakk! iChaakk!, las patas de los caballos". Otra interrumpía, estremeciéndose: “iAyy! ¿Qué será? ¿Espíritu será?” La primera evocaba ahora el sendero exacto por donde pasaban los caballos de los santos: un lugar preciso en el río, el crujir de las yerbas acuáticas. Las mujeres eran excelentes narradoras, recreaban a la maravilla los ambientes y las tensiones, floreciendo en esos relatos, que los hombres escuchaban con placer como si los oyesen por primera vez.

Iniciaron, entonces, las invocaciones a las santas o $m a-$ mitas. Una a una fueron siendo recordadas, tratando de no olvidar a ninguna. Un kamayoj repartió el alsa (la cena ritual) que consistió en interiores semicrudos en honor a los vientos, mientras el otro, junto con el putira, sacando los paris angila de sus chuspa, salieron fuera del templo para invitar a los samiri (potencias gestadoras de la naturaleza). ${ }^{18} \mathrm{~A}$ su regreso, las invocaciones y ch'alta variaron una última vez: fueron ahora los mallku (dioses tutelares) de las chacras y las virgina (la parte sagrada femenina y plural que protege las tierras cultivadas), los recordados para "un buen año" y "bendición” de la siembra.

Al atrapar a los vientos, los chipaya habían intervenido modificando el clima. Una vez calmados los soqo y facilitada la llegada de la lluvia, sería asunto de otras potencias sagradas como mallku, samiri, virgina, el producir una buena cosecha.

Los vientos permanecen dos o tres meses cautivos en el templo. Primero junto al altar, y luego, detrás de la cumbrera de la puerta de entrada. Pero si el verano es demasiado lluvioso y el río Lauca amenazara con inundar las chacras o el pueblo, las bolsas serán abiertas y los soqo puestos en libertad, alejando el peligro al empujar las nubes húmedas hacia el oriente. Antiguamente, incluso, se realizaba una ceremonia inversa a la de atajar al viento llamada "adoración", para pedirle que soplara en los meses sin siembra, o que formara las dunas en Aypa-

\footnotetext{
${ }^{18}$ De evidente origen aymara, como gran parte de la terminología religiosa chipaya, la palabra samiri podría traducirse como "él que es felicidad" (sami= alegría, y el sufijo $r i=$ el que ejecuta la acción). Los samiri pueden ser amuletos de animales o de personas y tienen diversas representaciones; piedras, gatos monteses embalsamados, etc. Sus significados parecen muy cercanos a los del término illa (Manríquez 1999).
}

ravi, o alejara las lluvias con granizo. Esa ceremonia ha caído hoy en desuso.

\section{La ceremonia como texto}

La ceremonia de "amarrar al viento" fue, inesperadamente, una gran sintaxis narrativa, articulando diversos personajes e historias particulares. Quizás, constituyó el punto de partida de aquella impresión de que un conjunto significante, con un sentido ecológico espacial, establecía relaciones no solo entre las dos historias de los vientos, sino entre ellas y otros relatos.

Aunque la ceremonia se manifestó en distintos lenguajes (palabras, acciones, gestos, perfumes, ruidos, sombras, etc.), todo se organizó en torno a un solo gran programa narrativo. Los sujetos de este programa eran ahora los hombres, y ya no los personajes de ficción, y su objeto de valor "la salvación de la siembra". Y es al interior de ese programa narrativo que se juntaron las dos historias de los vientos con La historia de los Caballeros, recordada por las mujeres a través de algunas frases, y por último, un tercer relato sobre los soqo que surgió a partir de las invocaciones de los hombres y que podríamos llamar $E l$ mito de sus recorridos.

Los vientos y el zorro formó parte, junto a las otras ofrendas (coca, phits, asado de culo, etc.) de un programa parcial, de "manipulación", que en este caso, fue una seducción: atraer a los soqo para que cayeran en la trampa. El hecho es que, una vez estando prisioneros, ya no se recordaron más sus hazañas con el zorro.

En cambio, El viento y las vicuñas no fue narrado esa noche: ihubiese ofendido el orgullo de los soqo! Pero estuvo todo el tiempo presente guiando la lógica de la ceremonia. Ese relato fue parte de la "adquisición de la competencia". De esa historia los chipaya extrajeron un "saber": si el pasajero burló una vez a los vientos, los hombres reunidos en el templo de San Santiago podían repetir nuevamente esa prueba. Conociendo su carácter ingenuo y su placer por los alimentos, fue posible no solo atraerlos, sino que, aún amarrados en bolsas, hacerse perdonar y tratar, incluso, que escucharan el ruego de detenerse.

Pero todo este primer episodio de capturar a los vientos se realizó bajo la venia de Tata Santiago y de su "herma- 
no" San Felipe, montados ambos en sus caballitos de yeso. El incienso, los rezos y la cruz, fueron esta vez los elementos para conseguir su permiso. Y una vez terminada la ceremonia, las bolsas de nylon se dejaron en la iglesia bajo su custodia. En esa primera gran unidad del programa narrativo, los santos actuaron como ayudantes de los hombres. Pero inmediatamente después, se iniciaron las acciones con la mano derecha y se recordó la historia de la llegada de los Caballeros al pueblo. Los manipulados fueron ahora los santos para que, aprovechando la detención de los vientos, avanzaran con la lluvia.

La ceremonia estableció así una relación de contradicción entre los Caballeros y los soqo: si los vientos del oeste avanzan, las nubes húmedas del oriente - gobernadas por los Caballeros- no pueden hacerlo. Se trata de una relación polémica, donde los vientos son el antisujeto o los antagonistas de los Caballeros: en esa época del año, el objeto de unos es justamente el objeto contrario de los otros. Los soqo desean que esté seco, los santos, que esté húmedo.

Las relaciones sintácticas provocadas por la ceremonia no se detuvieron allí. Las invocaciones a los lugares por donde pasa el viento pronunciadas con voz implorante: “iSojalla!”, etc., fueron localizando con precisión un paisaje, al mismo tiempo que diseñaban, como supuesto dominio de los soqo, un territorio muy amplio que va desde las costas del Pacífico hasta el altiplano. Esta imagen territorial se hizo más concreta y compleja en otros relatos que obtuvimos sobre los viajes de los vientos después de haber asistido a la ceremonia.

\section{Los recorridos de los soqo}

A pesar de situarse en una geografía tan real y de aludir, a menudo, a experiencias directas del narrador ("los he visto", "los he sentido soplar", etc.), los recorridos constituyen, innegablemente, un tercer mito sobre los vientos. La percepción natural ha sido elaborada de tal manera, que el resultado es un "texto construido", que lleva además, como todo texto mítico, un segundo sentido, hablando de otras cosas que del mero pasar del viento por algún camino. Se trata, como veremos, de recorridos con rasgos extraordinarios.

¿Cómo son pensados estos soqo en el juego del relato? No se dice solamente que vienen del oeste, así, vagamente, sino que de muy lejos, desde el litoral chileno, y se fijan puntos más o menos definidos donde tienen su nacimiento. Recordemos que durante la ceremonia, una invocación hacía formarse a los vientos en un corredor al sur de Iquique, mientras que el gesto de quien los invocaba, quien paralelamente extendió sus palmas, hacía presumir que ese corredor era un espacio muy estrecho. En otros relatos de los viajes de los soqo, el lugar puede variar, pero es siempre en la costa y siempre preciso: “...de un lugar en el mar de Camiña, ${ }^{19}$ que yo conozco, nacen los soqo. Los he visto nacer... Y así, los he saludado: isoqo!". Y no solo nacen sino que al hacerlo tienen, incluso, una forma y un color: “... del océano Pacífico viene ese soqo. En forma de takia (estiércol), así, negrito y redondo sale del mar..." (Santiago Condori, relato recogido por la autora).

Más aún, tienen una "muerte". Al llegar a la alta cordillera, los soqo se dividen en dos: los que se van hacia el sur de Chipaya, hacia el lago y salar de Coipasa, y los que van hacia el norte, dando vueltas por el volcán Wallatiri y el lago Chungara, pasan al altiplano boliviano cerca de Turco. Y se unen de nuevo para tener un final común, en un límite hacia el este que los relatos sitúan con toda precisión en Pampa Aullagas, en las riberas del lago Poopó: "Ahí muere. Ahí termina".

Por último, los vientos no tienen sus rutas independientes, siguen los mismos senderos que utilizan los hombres:

"Antes cuando era niño, los putira sabían decirme: el viento siempre viene por los senderos de las llamas... por esos caminitos que antiguamente recorríamos para subir desde la costa [...] A estos caminitos dicen que sabían ir los sukachiri a amarrar a los soqo, cuando estos vientos estaban corriendo..." (D. Flores, relato recogido por la autora).

El encuentro del "pasajero" con la señora del viento, en la primera historia, materializa, da realidad a este compartir de caminos entre los soqo y los hombres, caminitos que son, a veces, pequeñas huellas solo conocidas por los que

${ }^{19}$ Camiña: Pueblo situado en un valle de la precordillera chilena, y por lo tanto, no tiene mar. Ese valle intramontano es uno de los lugares más frecuentados por los chipaya en sus descensos en busca de trabajo temporal. El "mar de Camiña" es el sector del océano Pacífico situado frente a la desembocadura del valle, hasta donde no necesariamente los chipaya se aventuran, pero que constituye una de las referencias espaciales necesarias al mito. 


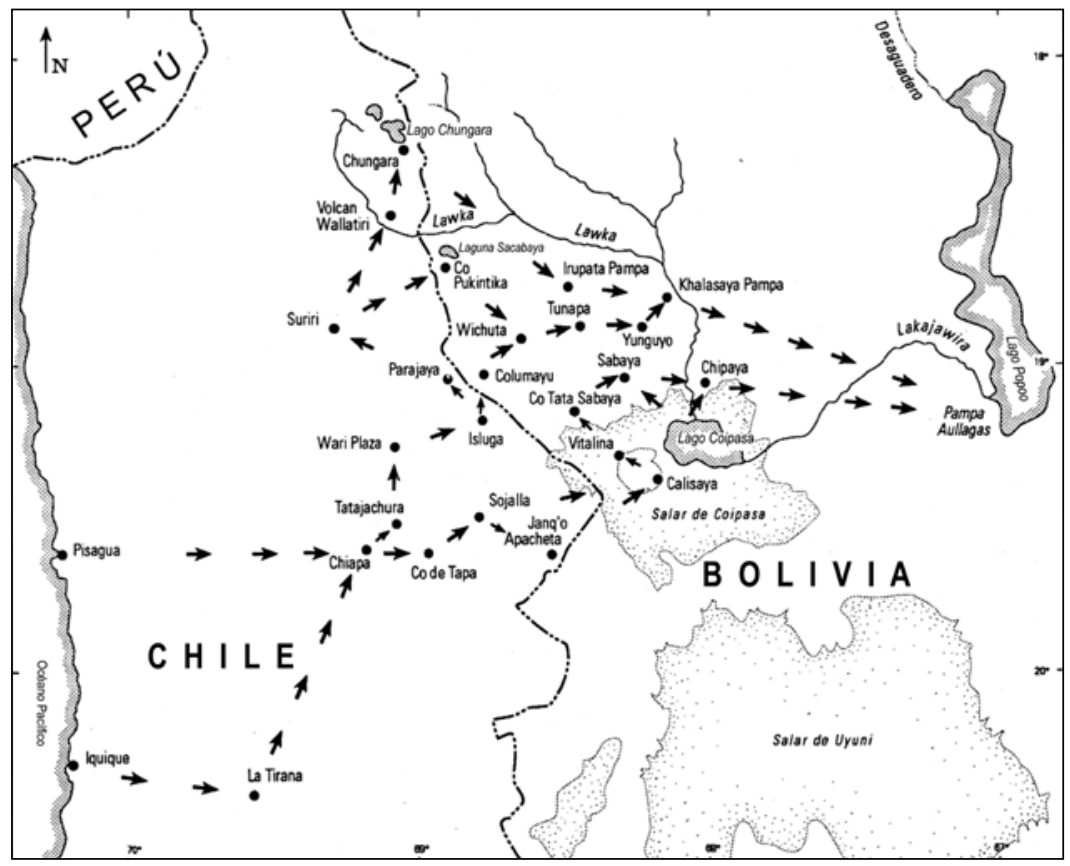

Figura 3. El recorrido de los soqo.

transitan a pie. Los vientos no van así a campo traviesa y quizás por dónde, sino por rutas reiterativas y lugares precisos, aunque siempre dando vueltas. Porque: "rotativo anda" y, "más o menos curvo viene".

Esa constricción mítica de los soqo a puntos muy concretos, crea naturalmente una fuerte iconicidad. Esos lugares tan conocidos permiten anclar a los soqo en una realidad vívida. ¿Por qué no tienen los vientos sus caminos propios, tan extraños y extraordinarios como ellos mismos? Al soplar por esas rutas "que antes recorríamos para subir desde la costa" ino va sugiriendo el texto una intimidad, una identificación, entre los soqo y los hombres? (Figura 3).

Con los relatos de los recorridos, los tímidos paisajes -los entornos concretos captables por la experiencia directaque enmarcaban las dos primeras historias, se van transformando en una extensión más abstracta, construida en la mente por una suma de experiencias o referencias sobre lugares, que va llenando las distancias entre los puntos mencionados, de acuerdo al saber o conocer un determinado territorio. Los recorridos van destacando ciertos puntos: mar de Iquique o de Pisagua; La Tirana, en la pampa; Janq'o Apacheta y Tapa Apacheta, en el camino a Isluga;
Jachura, Wichuta y Kayku, en los alrededores de Chiapa; Columayu, Tres Cruces, Paris Qota, Wari Palaza, en los senderos de subida de la precordillera; Isluga, Sojalla, Kinsachata, Suriri, Parajaya, en plena cordillera. Hacia el norte, Wallatiri y Chungara. Pasando al lado boliviano: Arintika, Pukintika. Y en el atiplano, Turco, Corque, Pampa de Sabaya, Pampa de Thunapa; Opatita y Yunguyo, en Huachacalla. Hacia el salar de Coipasa o su isla, Paraya, Vitalina, Calisaya. En los alrededores de Chipaya, Wichuta, Payrumani, Jisk'a Paraya Pampa. Mientras se imponen, simultáneamente, límites arbitrarios al soplar de los vientos.

Hay pues, una evidente intención de crear la imagen de un espacio, y decimos crear, porque se trata de una selección voluntaria de puntos geográficos relacionados. Curiosamente, hacia el este, hacia el clima gobernado por los Santos Caballeros, no parece haber lugares con historias y los jarqawi, los vientos tibios del oriente, no son tratados como personajes. Es, pues, un espacio asimétrico, donde la comunidad no constituye el centro y se encuentra situada en uno de sus bordes.

A los problemas planteados por la presencia de una imagen espacial, los relatos de los recorridos agregan uno más: 
muchos de los lugares mencionados no son exclusivos de los soqo, sino compartidos con los recorridos o hábitat de otras deidades. Es el caso, por ejemplo, del paso de los vientos por el pueblo de La Tirana, ubicado en plena Pampa del Tamarugal. En uno de los relatos, el narrador contaba que, bajando una vez a la feria que se realiza anualmente en este pueblo, sintió de pronto mucho frío pues el viento soplaba fuerte. Y desplazándose, logró ubicar un corredor, justo a un costado de La Tirana, por donde cruzaba el viento. Entonces, exclamó: "iPor aquí, por aquí había estado su camino de los soqo!" Como si precisar ese camino fuese cosa de gran importancia. Si él pudo identificar a los vientos y definir su vía, es porque la tradición hace del pueblo de La Tirana un camino obligado de los soqo. Más aún, se dice que es una de sus kamana (lugar donde descansan, comen, y moran por un tiempo), desde donde toman fuerzas para remontar las alturas cordilleranas. ¿Por qué la elección de este lugar y no de otro cualquiera del desierto, como morada temporal de los vientos? Se dice que allí, en tiempos antiguos, había una pukara chullpa. Es decir, había algún tipo de monumento considerado como perteneciente a una humanidad anterior (conocida como chullpa). Esta pukara era un mallku, una deidad protectora, llamado Tira Tirani, que adoraban los antepasados. ${ }^{20}$ Cuando el pueblo creció "con gentes extrañas" (según el narrador), ya no fue posible realizar esta adoración. Pero aún hoy, antes de acercarse a la feria, los chipaya saludan desde lejos a ese mallku sepultado bajo las casas (ver Figura 3).

Al pasar los vientos justamente por el pueblo de La Tirana, se produce una conjunción a nivel superficial, en las estructuras discursivas, entre el relato de los soqo y el breve relato sobre la pukara chullpa. ¿Solo una coincidencia de escenarios? Sin embargo, esta impresión de que una referencia voluntaria se está planteando entre historias diferentes, se convierte en certeza cuando examinamos las otras kamana de los soqo.

Porque si los vientos no van por cualquier parte, tampoco descansan en cualquier lugar. Se dice que sus dos kamana principales son, hacia el norte, en pleno cordón

\footnotetext{
${ }^{20}$ La existencia de este mallku Tira Tirani podría explicar el hecho de que el actual pueblo - sitio de algún antiguo culto- sea hoy día un importante lugar de peregrinación para la Virgen del Carmen, en la famosa fiesta de La Tirana. Hasta ahora, el nombre había sido explicado por una leyenda poco convincente, en la cual una princesa india se enamora de un capitán español.
}

cordillerano, el hermoso lago Chungara; por el sur, ya en el altiplano, la laguna y el salar de Coipasa. Estas dos kamana llaman poderosamente la atención porque se vinculan directamente al origen y naturaleza del río Lauca que permite la vida en las saladas y frías pampas de Chipaya.

El Lauca brota de pequeños riachuelos en las inmediaciones del lago Chungara; pero las concepciones chipaya hacen nacer al río del lago mismo o, al menos, siendo el colector de sus aguas subterráneas. Después de muchas vueltas y de recibir otros afluentes, el Lauca atraviesa las tierras de la comunidad para desembocar en el salar de Coipasa, lugar que es también el extremo sur del recorrido de los soqo y su kamana principal. Se nombran, aquí, varios lugares donde los vientos descansan: Aya Tiya, Villa Vitalina, en la isla en medio del salar y dos agujeros míticos llamados qori lakani (los con "boca de oro"), que se supone, ubicados igualmente, en el Coipasa. Pero estos dos descansos de los vientos -Chungara y Coipasa- son al mismo tiempo, dos bellísimos infiernos, hábitat preferido también de otro importantísimo personaje sagrado llamado saqra o demonio andino. ${ }^{21}$

¿Por qué habrían de pasar los vientos justamente por el pueblo de La Tirana, apenas un punto en el inmenso desierto, habitado ya por otro personaje, ese mallku Tira Tirani? ¿Por qué descansan en los qori lakani, los más demoniacos y peligrosos de todos los lugares con saqra, habiendo tantas otras posibilidades? No podemos menos que reconocer la evidente intención de establecer puntos de enlace entre los desplazamientos o moradas de diferentes personajes, creando así un ámbito común.

Todo lleva, entonces, a pensar que el espacio -yendo más allá de cada historia en particular- se está construyendo como un tema independiente al reencuentro de los distintos escenarios de cada deidad. Esta imagen espacial, que traspasa el mundo cerrado de cada texto, sugiere que los paisajes, los lugares, los ambientes, están jugando un doble papel: por una parte, de escenario de las acciones al interior de programas narrativos específicos (de los soqo, del saqra y de los Caballeros, etc.); y por otra, de construir

\footnotetext{
${ }^{21}$ Saqra: Deidad de las profundidades, frecuentemente asimilado al demonio cristiano, aunque diferente a éste por ser dador de riquezas y bienes. No se define tanto por su maldad sino, más bien, por su peligrosidad. Mucha cercanía atrae la pérdida de la conciencia o la locura.
} 


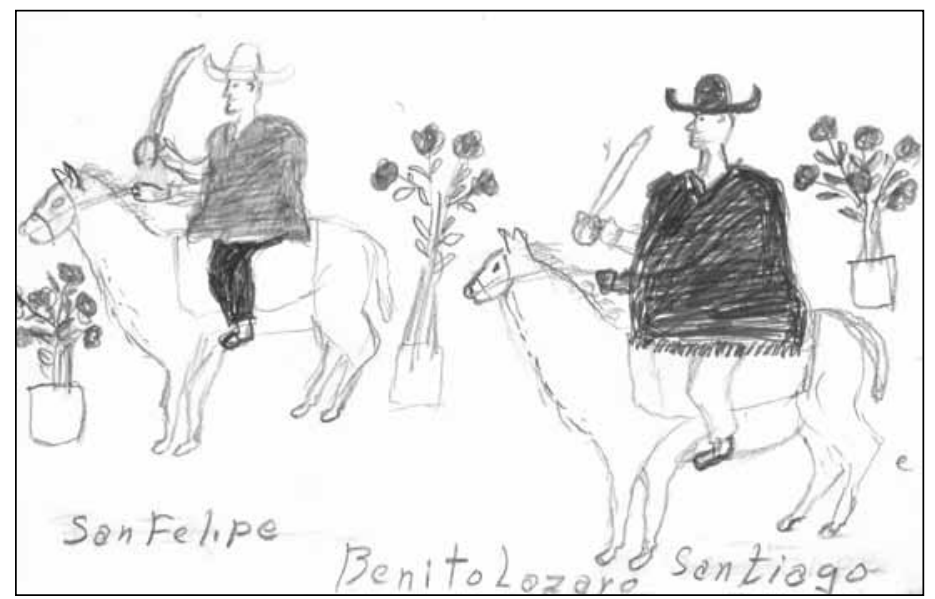

Figura 4. Los Santos Caballeros. Dibujo de Benito Lázaro, comunero de Chipaya.

en su conjunto, un mapa más amplio que determina, necesariamente, una segunda lectura.

Estamos, entonces, ante la presencia insinuada de un texto ecológico geográfico, de un mito independiente, formado exclusivamente por las referencias espaciales entre relatos. ¿Qué nos autorizaría a darle derecho a ser si no lleva palabras propias ni es narrado como tal? Todos los personajes sagrados que se encuentran enlazados a través de los lugares tendrían que desempeñarse -además, o a pesar de sus quehaceres personales- como sujetos colectivos de un programa narrativo común: la determinación de un espacio. Un macroprograma, correspondiente a un macromito englobador. ¿Es posible formular este programa?

El mapa está allí, sin embargo, desplegándose en la mente de los que escuchan los relatos. ¿Para qué dibujarlo en la memoria? ¿Cuál sería su sentido, su importancia, si se extiende tanto más allá de los actuales límites de la comunidad?

\section{* La construcción de UNA imagen espacial}

\section{El espacio en las historias de los Caballeros}

Las diferentes versiones de la historia de los Caballeros pueden organizarse en tres variantes, dos de ellas narrando el suceso mismo de la llegada de estos santos a las pampas regadas por el río Lauca, allí donde después se levantará el pueblo de Santa Ana de Chipaya, y una tercera variante que explica las causas de esa llegada y que participa más directamente en la fundación de un clima y de un territorio. Demos una rápida mirada a las dos primeras (Figura 4).

Variante 1. Los Caballeros simplemente llegan (lo que escuchamos ya parcialmente durante la ceremonia). Esta variante comienza siempre con la presencia de una pareja de antepasados -Juan Machaqa y Ramusa Choqo- que habitan el lugar que hoy es Awaqota. Allí pasa un río y ellos se alimentan de una raíz acuática, el khiwi, que tal como veremos más adelante, de ella se alimentaron los chullpa cuando se lanzaron al río para salvarse del calor tan intenso que produce la brusca salida del Sol.

"Tenían un perrito chico y ese perro dice que ladró. Entonces, “qué está ladrando este perro?’ dice que saliendo del río, dice que le vio [notemos que en este relato los antepasados aún viven en el río]. Venían cuatro Caballeros montados en caballos [...]. Entonces, el perro ladró y después [...] dice que ahí se entraron ellos al río".

Los Caballeros vienen por el río y en varias versiones se especifica que ese río era uno de los brazos del Lauca que antiguamente dividía las dos mitades del pueblo. Los Caballeros vienen, entonces, por el centro mismo del territorio chipaya. Una y otra vez el perro ladra y ellos aparecen y desaparecen. 
“Se desapareció totalmente, dice. ¿qué estará andando? ¿Será un fantasma?', dice que dijeron... 'Estaban viniendo cuatro Caballeros, está andando fantasma', dice. Entonces, ellos volvieron a comer el khiwi. [...] En ese lugar, dice, que habia un pequeño tolar. Después de unos cuantos días, en medio del tolar, se encontró un caballero montado, así pequeño, como juguete...".

En otras versiones, lo que encuentran es un caballito de oro. Y los antepasados dijeron: "Esto debe ser Caballero, debe ser milagro".

Lo llevan a su casa y lo perfuman con incienso. Así comienza la veneración: se trata de San Santiago. Los otros Caballeros son encontrados en distintos lugares y en algunas versiones esto se explica porque "dispararon" hacia los cuatro lados, al ser asustados por el ladrido del perro. San Santiago y San Felipe se "milagraron" en Tajata (mitad de arriba), mientras que San Jerónimo y Yunguyu fueron encontrados por los Twanta (de la mitad de abajo) en medio de otros tolares (D. Flores, relato recogido por la autora). ${ }^{22}$

No se sabe quiénes son estos jinetes hasta que una persona, en su embriaguez, escucha que los Caballeros le hablan y le avisan sus nombres. Una capilla es construida en el lugar de cada "milagro".

Variante 2. Los Caballeros no llegan, caen o aparecen.

"Los Caballeros bajaron o cayeron... ¿Qué será? Junto con los relámpagos bajó una estrella y paró una muralla. Una muralla blanca. Una persona había visto y avisado. De ahí hicieron levantar los templos. [...] Muralla siempre cayó, como estrella caída. Con el relámpago, un caballito mismo de oro ha aparecido. Dos [caballitos] en Tajata, dos en Twanta... En sueños ya después se han soñado [con los Caballeros]: 'Yo he llegado. Soy Santiago. He de vivir con ustedes' [...]. Nuestros abuelos los han criado a esos santos parando calvarios, iglesias... De puro sueño han sabido" (V. Huarachi, relato recogido por la autora).

Los cuatro Caballeros -que en una versión poco frecuente, son solo tres- disparan o caen en cuatro puntos diferentes, dos en Tajata, la mitad de arriba de la comunidad, dos en Twanta, la mitad de abajo, marcando ciertas orientaciones

${ }^{22}$ Yunguyu: No deja de extrañar este santo con nombre aymara (seguramente yunka uyu, "corral caliente"), evocando el mundo terrestre, y sin embargo, asimilado a los Santos Caballeros. No sabemos si en otras regiones este santo es también venerado. fundamentales. Se da así un origen mítico a la organización espacial que diseñaban, hasta hace muy poco tiempo, las capillas y calvarios de santos. Además de la iglesia central perteneciente a toda la comunidad, en cada uno de los ayllu que formaban las mitades había capillas ubicadas en el pueblo. Desde cada una de ellas, en línea recta, salían hileras de calvarios - llamados cilos (cielo)- dirigiéndose hacia los cuatro puntos cardinales. Sus terminales eran otras capillas ubicadas ya en la periferia, en el lugar donde se sitúan las estancias (viviendas y pastizales dedicados al pastoreo). ${ }^{23}$

Rescatemos de las primeras versiones algunos breves datos espaciales: los jinetes llegan por Awaqota, punto situado al norte del territorio chipaya, insinuándose en su movimiento una dirección norte-sur. Vienen por un río, por lo tanto ese río, que es el Lauca, ya ha sido "creado", problema al que ya regresaremos. Y vienen por el centro, "disparando" en cuatro direcciones. Parecen fundar así el paso de ese territorio donde más tarde se edificará el pueblo, de un estado de indeterminación a un estado de sociedad, ordenado en mitades y orientado hacia los cuatro puntos cardinales: un espacio social inscrito en el interior (aunque en uno de sus bordes), de ese amplio territorio determinado por los soqo y otras deidades.

Variante 3. Los Caballeros son los "enviados" de Jesucristo.

"Dicen que se había pensado el Jesucristo: "Con qué voy yo a ganar este mundo? Entonces nombraremos a San Santiago, San Gerónimo, San Felipe y Yunguyo'. Los cuatro militantes [imilitares?] había nombrado. Yentonces 'esos serán dirigidos por mí, el diablo que no me ataque'. Entonces el Jesucristo había enterrado al diablo, tres días, por Pascua. ${ }^{24}$ Entonces, dijo [Jesucristo]: 'Usted va a ser San Santiago'. Había nombrado un Caballero... 'Ya, ilisto! [...] Usted va a ser mi operario, usted va a pelear junto conmigo, mucho me están atacando. Usted va a estar conmigo hasta que gane el mundo. Usted va a hacer milagros porque aquí van a haber humanos'... 'Dónde puedo ir?', dice que había dicho el Santiago. 'Usted no va a vivir en la tierra, va a andar andando junto con las nubes... Así el diablo a nadie va a agarrar. Cuando el diablo esté engañando... vas a encender un fuego, vas a apuntar [con el] rayo... ishhhiyinnn!"”.

${ }^{23}$ Para una descripción detallada de este sistema de cilos y otras organizaciones espaciales que existieron antiguamente en torno al pueblo de Chipaya, ver Wachtel (1990).

${ }^{24}$ Este término "diablo" que es utilizado a veces, cuando la narración es en castellano, es reemplazado por saqra en las versiones en idioma nativo, o incluso en otras versiones españolas. 
$Y$ de esa vez había mandado a los abuelos que adorasen a esos Caballeros. [Los abuelos] se habían pensado: 'Entonces, haremos igualito a gente, con caballo, con su sablecito, con su armamento, ilisto!' Entonces, habían hecho. Los machu [antepasados chullpa], habian hecho.

En ese momento el rey Inka se había puesto en contacto con el Jesucristo. 'Bueno, ya, que haya en todo el territorio boliviano esos santos, Santiago, San Felipe... en cada pueblo'. Entraron en acuerdo. 'Que hagan milagro', dijo el Jesucristo... Cada pueblo había hecho [a esos santos], grande, chico...".

Y aquí el relato se entronca con las variantes anteriores "un crucecito había aparecido en el lugar donde estaba San Gerónimo..., etc." (D. Flores, relato recogido por la autora).

El aporte espacial de las historias de los Caballeros. Será el papel de vigilantes del saqra el que destinará a los Caballeros a las nubes, especialmente a aquellas de las tormentas eléctricas, que producen rayos. Es por este papel de gobernadores del clima lluvioso del oriente, que quedarán definidos en una posición este, opuesta al oeste de los soqo.

Pero hay algo más, con esta posición este, los Caballeros marcarán un límite a todos los territorios recordados en los mitos: un límite impreciso hacia extensiones no mencionadas en los relatos ni por nombres de lugares, ni por ríos, ni por cerros específicos, ni siquiera por las acciones de algunos personajes. Un límite hacia el oriente más allá del cual se acaba la importancia de una memoria del paisaje.

Podemos percibir, así, una oposición entre el espacio del este y el espacio del oeste. El primero nebuloso, sin imágenes definidas, sin recuerdos, por así decirlo; el segundo, finamente dibujado, con historias, susceptible de ser pensado. Entre ambos espacios, un punto de contacto: las pampas de Chipaya.

Programas narrativos englobantes. La tercera versión plantea relaciones entre los Caballeros -que aparecían como sujetos aislados en otras versiones- $y$ los personajes de otras historias. Estas relaciones son polémicas y sugieren la presencia tácita de estructuras narrativas que enfrentan a los santos con sus antagonistas. Situando a los Caballeros como gobernadores de las nubes y el rayo, esta versión establece una referencia velada al conflicto ecológico entre vientos y Santos Caballeros, que dio sentido a la ceremonia. Pero es con el saqra que la tercera versión plantea una oposición explícita. Sabemos, ahora, que los Caballeros llegan a la pampas de Chipaya, enviados por Jesucristo, para combatir al saqra. Serán las supuestas acciones del saqra -que se narran en otra historia- las que provocan este combate. La lucha contra el saqra será uno de los programas narrativos principales de los Santos Caballeros (aunque posteriormente los chipaya los adoraran y "criaran", según un informante, para que los protegieran también de diversos males).

Los Caballeros están en combate permanente con el saqra. Esta situación de tensión es recordada por algunos dichos como: "Si el rayo cae en un lugar, ahí seguro hay saqra", es decir, el lugar tiene un carácter semidemoniaco. Recordemos que durante los preparativos para la ceremonia de amarrar a los vientos, el putira abrió el cofre que se guarda en el altar y desató una talega que contenía las piedras llamadas walas. Esas walas (balas) -objetos redondos de metal, antiguos proyectiles de guerras pasadas o de ejercicios militares, difíciles de encontrar-cumplen el papel simbólico de proyectiles de los santos contra el saqra.

Pero hay también, un relato muy particular que narra lo que podríamos considerar la batalla primigenia, vivida entre los santos y el diablo, a consecuencia de la cual se va fundando el territorio chipaya y que cierra, con los límites en los que se desenvuelve, aquella imagen espacial que estamos persiguiendo.

\section{Los aportes territoriales de la historia del saqra}

Entre todos los relatos chipaya, hay dos que resultan excepcionalmente interesantes ya que el "enunciador" de estos mitos, se sitúa claramente en una perspectiva diferente que el "enunciador" de los mitos aymara, que tratan del mismo tema. Uno de ellos, es Los vientos y el zorro donde los personajes importantes, como vimos, son los vientos y no el zorro; el segundo es la historia del saqra que abre los ríos Desaguadero y Lauca.

Todo comienza en el lago Titicaca, y muchas veces, concretamente en Copacabana. Unas variantes relatan que "el saqra la pisó a la Virgen de Copacabana". Otras veces, se dice, en cambio, que es "la señora de Copacabana, que es la Virgen de hoy" la que pisó al diablo, "entonces el diablo quería escapar". Como sea, San Miguel, con su espada, comienza a perseguirlo. Para huir, el diablo va 


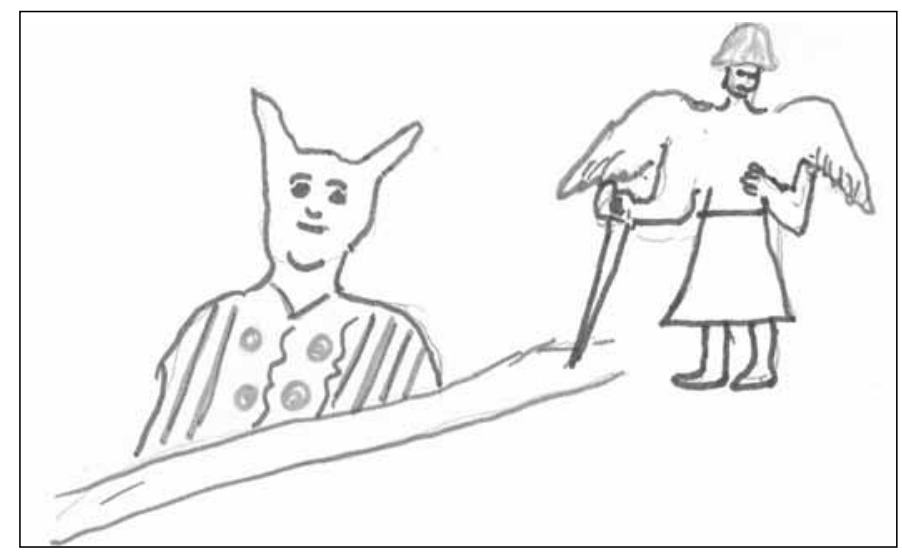

Figura 5. San Miguel persiguiendo al saqra. Dibujo de Martín Quispe.

cavando la tierra con un temblor. Por ese canal, se van desbordando las aguas del Titicaca y se va formando el río Desaguadero. Se trata de una versión opuesta al conocido relato sobre Tunupa, que siendo una deidad precolombina, la versión españolizada colonial lo transforma en un santo que, flotando sobre las aguas (en una balsa o en una manta), abre el río Desaguadero (Ramos 1976). Es justo a la inversa del saqra que va cavando la tierra con un temblor para formar voluntariamente el mismo río (M. Quispe, relato recogido por la autora en 1982). ${ }^{25}$

Algunas variantes se inician cuando el saqra declara: "'He venido para abrir río', lo que asusta a San Miguel: 'iSaqra está haciendo río del infierno!'”, y esto motiva la persecución. La formación del Desaguadero y de todo el sistema acuífero que va surgiendo a continuación, es el tema fundamental de los relatos. También una serie de lugares van apareciendo aquí, nombrados con detalle, y recordando el efecto de realidad que provocaban los recorridos de los vientos. De vez en cuando, el saqra emerge y San Miguel logra "pisarlo", volviendo a perderlo cada vez que el saqra se hunde: "El diablo se salió en Chullasa, que se formó el lago Poopó, en ahí, San Miguel lo pisó” (M. Quispe, relato recogido por Porterie-Gutiérrez). "Y en eso dice que lo tocó al diablo con su espada que en medio del lago [se formó] una isla..." (versión de la misma fuente, recogida por la autora; Figura 5).

\footnotetext{
${ }^{25}$ El mito chipaya donde el saqra abre los ríos, superponiéndose a la imagen tan prestigiosa de Tunupa, sugiere la dimensión igualmente prestigiosa y sagrada que tiene el saqra en el pensamiento chipaya.
}

Vemos, a lo largo de esta persecución, cómo se forma tanto el río Desaguadero que vierte las aguas del Titicaca hacia el lago Poopó, como el propio Poopó y sus islas. La huída sigue luego por la ribera del lago, y otros santos cooperan para detener al saqra.

"Entonces dice que esperó el señor de Exaltación y también se escapó... Hoy es una población de Quillacas [...] San Miguel, para pisarlo, lo buscó... Ahí lo esperó San Miguel con otros caballeros para matarlo..." (M. Quispe, relato recogido por la autora).

Y luego, el saqra comienza a abrir el río Lakajawira, que conecta el Poopó con el salar de Coipasa, acercándose al territorio chipaya: "En Pampa Aullagas [justo donde "mueren" los soqo] ha salido abriendo río. Un asta amarillo, el otro verde..." (J. Condori, relato recogido por la autora).

Y por eso, se dice, que un costado del río es fértil y el otro "puro pajonal". Cada vez que San Miguel logra "pisarlo", se van formando "pasajes" (angosturas) que permiten cruzar el río:

"Después al sur del lago Poopó apareció... al frente de Jarinilla hay un pasaje, en ese pasaje lo pisó... Después en el pasaje de Tunakipa... después, así, el diablo desapareciendo, apareciendo, perdiéndose, apareciendo, de esa manera se fue, después al oeste, con muchas curvas se fue... los ríos del diablo eran impasables. Un solo pasaje hay en Tunakipa... otro es el Niqru Pasaje [el pasaje negro]... esos pasajes ahí donde [lo] había pisado San Miguel. Si no hubiera pisado San Miguel, no se podría pasar. Siempre al infierno va ese río" (D. Flores, relato recogido por Porterie-Gutiérrez). 
A su vez, el saqra va pisando los cerros que se le oponen, derribándolos, transformándolos en sus formas.

"Y después dice que [lo] esperó un cerro chico, y a ese cerro dice que lo repartió en mitad [...]. Entonces, el cerro Coipasa y el cerro Jach'aqollu, hombre y mujer, lo esperaron. Después al cerro Jach'aqollu el diablo dice que le botó pierna abierta... Así ese cerro Jach'aqollu tiene dos puntas... Y después el cerro Coipasa dice que era grande, la mitad dice que entró al suelo, dice que se ha hundido..." (M. Quispe, relato recogido por Porterie-Gutiérrez).

El saqra ha llegado al salar de Coipasa. Aquí ocurren dos transformaciones importantes: abre los qori lakani (los agujeros con bocas de oro que conectan ese lago con otras regiones), pero se asusta al ser observado por el cerro Jach'aqollu, que exclama: “iDiablo dice que ha venido! iUn canal haciendo, qori lakani haciendo...!". El diablo ya no puede seguir porque "cristiana gente lo ha mirado" (variante de J. Condori, relato recogido por la autora). ${ }^{26}$

El saqra se hunde entonces en las bocas de oro de los qori lakani. Y si no hubiera hecho ese hoyo: "Es muy profundo, ahí todas las aguas se juntan", los chipaya podrían estar completamente inundados. "Si no hubiera ese [qori lakani], este lugar podría ser pura laguna, entonces, ahí, ahora nos favorece". Mientras que San Miguel, persiguiéndolo siempre, "embarra" con sal al lago Coipasa, haciendo surgir el salar. Y como este lago y el salar de Coipasa están comunicados por pasajes subterráneos con el mar, resulta que "el océano Pacífico es un poco salado, porque agua salada [del Coipasa] desemboca por un pasaje subterráneo" (D. Flores, relato recogido por la autora). ${ }^{27}$

Hasta ahora, a raíz de la persecución, hemos visto nacer el Desaguadero, surgir el Poopó, el río Lakajawira y el salar de Coipasa. Desde aquí, se inician varios nuevos recorridos. El más importante para los chipaya será el camino que sigue el saqra desde el lago Chungara, en donde emerge después de sumergirse en los qori lakani, hasta nuevamente alcanzar el Coipasa, abriendo esta vez el río Lauca, siempre perseguido por San Miguel. Se trata, evidentemente, de un recorrido paralelo al primero, aunque ahora

\footnotetext{
${ }^{26}$ Los cerros pertenecientes hoy a poblaciones de habla aymara son, de este modo, incorporados a la batalla, pero del lado de los santos.

${ }^{27}$ Es pues, la consecuencia de esta batalla contra el saqra la que da su esencia al mar.
}

la intención del saqra de abrir los ríos parece más evidente y, más débil, la presencia del santo persiguiéndolo. El Lauca, que permite la vida de la comunidad, es, pues, un río demoniaco: "Este río es para nosotros, para mantención de nosotros y para mantención del ganado... El diablo para nosotros ha rompido [...] Saqra río, decimos... se llama río del diablo" (J. Condori, relato recogido por la autora).

Y su punto de origen, otro infierno, el Chungara (que algunos sitúan junto al volcán Wallatiri, aunque está un poco más al norte), tal como lo expresa el encanto de este breve texto: "Para que viva el indio, botaron el jalsuri [otro nombre del río, vertiente en aymara] desde el Chungara Wallatiri. Agua para nosotros irica agua del infierno viene!" (J. Condori, relato recogido por la autora).

Los relatos de este recorrido se completan con la creación de los afluentes principales del río Lauca, al emerger el saqra para impulsar el agua, tanto en Sajama como en Turco. Después de sumergirse en las bocas de oro del Coipasa - punto final obligado de sus movimientos antes mencionados- el saqra inicia también recorridos subterráneos más cercanos que van conectando lagos y salares: emerge en el lago y salar de Suriri, en Isluga, y en el salar de Uyuni, un poco más al sur del Coipasa; pero también, por debajo de la tierra, da saltos hacia puntos terminales que marcan los límites del espacio por él diseñado. Aparece, sacando su cabeza en San Pedro de Lípez, al sur del salar de Uyuni, y mucho más lejos aparece en Arica, en unas variantes, en Antofagasta, en otras (Figura 6).

En los dos primeros lugares, es atrapado y encadenado por el cura del lugar. Pero, como comentaba un amigo de Chipaya con mucho placer: "iHay tantos saqras! A uno, no más, lo habrán atrapado. Los otros andan por ahí dando vueltas...".

Ningún otro personaje, en otro relato chipaya, evoluciona más allá de los límites establecidos por el saqra. Él es, pues, el gran diseñador de un mapa que va desde Arica a Antofagasta por la costa y desde el Titicaca a Lípez por el altiplano. Dentro de este marco evolucionarán las otras historias contadas por los chipaya. Hay, pues, un recorte arbitrario -y por lo tanto, significativo- de la continuidad geográfica, en cuyo interior sucederán los acontecimientos trascendentes; no solo los recorridos de los soqo, sino también los viajes de las almas, las peripecias de los antepasa- 
dos míticos que sobreviven a la salida del Sol, los cambios de emplazamientos de algunos mallku, entre otros.

Este recorte arbitrario constituye, más allá de las historias, una suerte de mito espacial, construido únicamente, por una evocación en las palabras de otros relatos, es decir, por una "figura" ubicada en un nivel superficial del contenido. Sus contornos, esbozándose por las carreras y saltos del saqra y por ese oriente indefinido, desde donde provienen las lluvias. Y en su interior, los trazos dejados por las hazañas de otros personajes que muchas veces reiteran lugares o extensiones por donde, justamente, ha pasado el diablo. Una representación de un espacio único, coherente, que debería corresponder, también, a un significado único formado por una articulación semántica de los diferentes escenarios.

\section{* Persiguiendo un sentido}

\section{El espacio en el texto del saqra}

Aquí, la presencia del espacio es extraordinariamente compleja y participa, simultáneamente, de distintos niveles:

En el nivel superficial. El espacio está constituido por una cadena de escenarios sucesivos mencionados solo por un topónimo o por un topónimo y un accidente geográfico (p.e., el lago Poopó). Son los espacios-lugares (los topo) donde van desarrollándose las diversas acciones. ¿De qué lugares se trata? Unos son ampliamente conocidos, ubicados en las tierras de la comunidad o cercanos a ella. En estos casos, el cuenta cuentos, familiarizado con un paisaje, se explaya a veces para acentuar el efecto de "vivido" de las hazañas del mito: "El diablo pasó por Tunakipa. Ahí donde ahora hay un santito, ahí [el santito] hizo un puente. Si no hubiera esa angostura ¿cómo cruzaríamos el río?".

Algunas veces, como en este texto, el narrador se pone de parte de los santos que, alcanzando al saqra con su espada, permiten la formación de angosturas por donde es posible cruzar los ríos abiertos por el diablo. Pero, muchos otros textos mencionan también otros escenarios con los que no es posible plantear una articulación con una experiencia de lo real, como, por ejemplo, el mismo Titicaca, el Chungara y Antofagasta, entre otros, por donde muy rara vez se aventura hoy un chipaya. Se tuviera la impre-

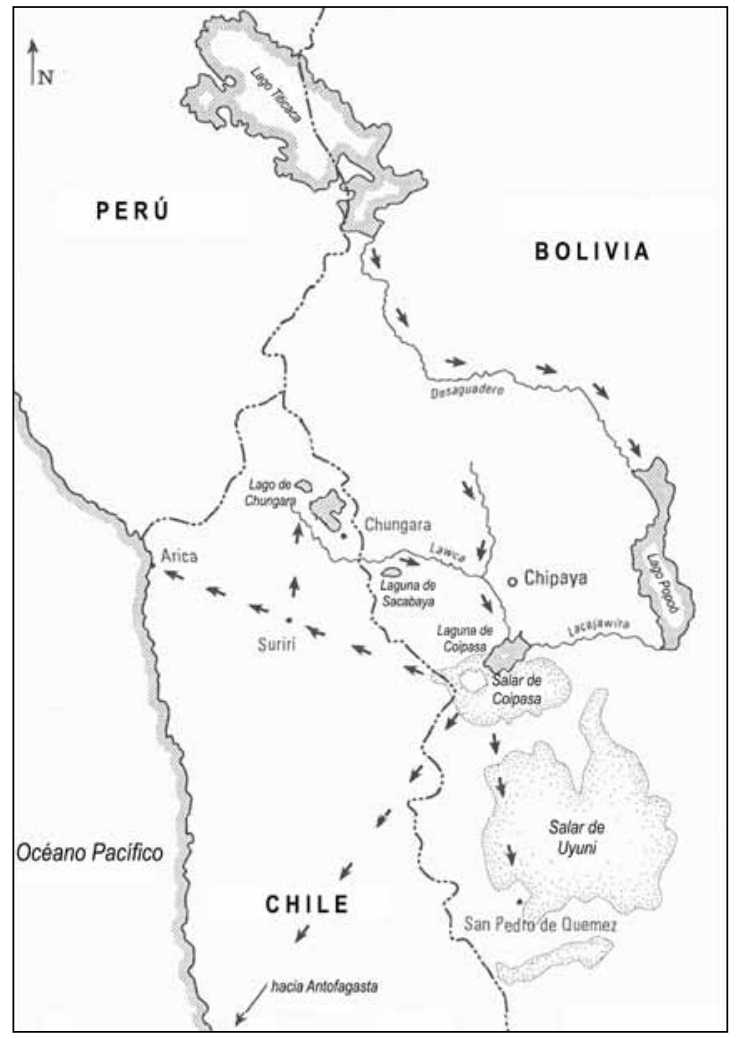

Figura 6. El espacio determinado por el saqra.

sión, así, de que los lugares conocidos proyectan un velo de intimidad hacia aquellos de los que se tiene apenas una referencia abstracta. ¿Se extiende el espacio mítico por este recurso discursivo, apropiándose de aquellos sitios desconocidos pero necesarios para la construcción del sentido? ¿O hay una oscura memoria - una memoria de memorias-olvidada ya como tal, que está enlazando esos lugares a un presente realmente recordado y vivo?

En las estructuras narrativas. En este nivel, el espacio deja de ser un escenario para tomar parte en las transformaciones mismas que ocurren en el relato. Podemos considerar que la huida del saqra perseguido por los santos, sea porque lo "pisa" la Virgen de Copacabana, sea porque tiene la intención directa de transformar el paisaje ("he venido para abrir río...", por la cual es también igualmente perseguido: “iSaqra está abriendo río del infierno!"), constituye el programa narrativo fundamental. En él se plantea una estructura polémica donde el objetivo que persigue el saqra es justamente el inverso del que persiguen los santos. De hecho, 
estamos denominando "santos" ahora a toda esta constelación semántica: Jesucristo, San Miguel, el señor de Exaltación, los Caballeros, y los curas que se oponen al saqra. ${ }^{28}$

¿Cuál es el "objeto de valor" que engendra la disputa? Podríamos definirlo de parte del saqra, como igualmente dotar a los futuros chipaya -que hasta ese momento anterior son solo machu o chullpa- de una ecología con humedad que les permitirá ser, existir. $\mathrm{O}$, tal vez, sin pensar en ellos, su objetivo es una aspiración compleja: hacer lo que quiera, ir donde quiera, es decir "ser como es, plenamente y en libertad". Y es precisamente ese ser en libertad del saqra (cargado de valores que no podemos desarrollar aquí), lo que los santos no pueden tolerar y deben reprimir.

Este programa narrativo principal se descompone en una serie de programas subsidiarios en los cuales el saqra, para lograr su libertad, va abriendo los ríos y los canales subterráneos, volteando cerros, haciendo nacer los lagos. Cada vez que es alcanzado por la espada de su perseguidor, lo "seco" transforma a lo "húmedo" y surgen las islas y las angosturas. También, San Miguel -como en un gesto de bautismo - transforma el Coipasa "embarrándolo con sal". Al finalizar la historia podemos percibir dos cambios fundamentales. Por una parte, un cambio en la relación de los protagonistas. De una situación de desequilibrio total se pasará a una frágil estabilidad. No hay vencedores ni vencidos. Al apresar San Miguel al saqra en Arica o en Lípez, pone punto final al enfrentamiento. Pero el saqra queda "por ahí dando vueltas", conservando una libertad disminuida: choques eventuales cuando cae el rayo darán cuenta de la actitud de constante vigilia de los Santos Caballeros, hacia el enemigo de Jesucristo.

Por otra parte, observamos un cambio que afecta al espacio mismo. Después de la historia del saqra podemos decir que un espacio ha sido creado y que podemos percibir esta creación desde dos perspectivas distintas. Un nuevo paisaje surge bajo el efecto de los cerros derribados, de la creación de ríos, lagos y pasajes subterráneos, de los terrenos ahora salados. Queriéndolo o no, el saqra y los santos son los sujetos de la transformación de este paisaje. Todo el curso de los ríos y los canales interiores

\footnotetext{
${ }^{28}$ Recordemos que "San Miguel lo esperó con los otros Caballeros", entre otras expresiones que hacen participar a los Caballeros en la persecución al saqra.
}

que comunican las aguas juegan el papel de un sujeto pasivo que ingresa a la estructura narrativa como un actor más, aquel que sufre cambios a raíz de las acciones que han ejecutado otros.

Pero otras partes del espacio mencionado en la historia parecen inconmovibles: el lago Titicaca, el mar, Arica y Antofagasta, y el lago Chungara. No se forman en la batalla, parecen haber estado allí desde siempre. Y sin embargo, podemos percibir también un cambio en este segundo escenario. Al ser utilizados por los protagonistas, los lugares y las extensiones entre ellos emergen de la nada de un mundo sin forma para integrarse al pensamiento de un espacio único, que la memoria distingue de un más allá no incluido en los relatos. Todo el espacio del saqra es, pues, un espacio creado.

En las estructuras profundas. Y es justamente en esta extensión que se articularán dos posturas irreconciliables: los santos y el diablo lograrán convivir, repartiéndose el tiempo y los lugares. Sus dominios quedarán definidos según las horas del día o las épocas del año, pero también según la geografía y el clima. Los santos, al este de las lluvias, y en el espacio social del pueblo y sus alrededores; el saqra, el oeste, los exteriores naturales y sobre todo, los lugares con agua y las conexiones subterráneas hasta el mar. Desde el punto de vista de esta historia, el espacio es el espacio de la conjunción religiosa. Y ese sentido debería participar en un sentido final para esa imagen de un territorio, con las otras historias que lo recorren.

\section{Reiterando un escenario: La historia chullpa}

Ocurre justo en el curso inferior del Lauca, abierto tan trabajosamente por el diablo.

Los sucesos de la historia. Junto a los relatos del saqra y de Los vientos y el zorro, es un tercer texto extraordinario. Todas las historias que se cuentan sobre la existencia de una humanidad anterior que vivió en un tiempo de penumbras, se plantean desde el punto de vista de una humanidad actual, surgida después de la existencia del Sol. Por lo tanto, son versiones sin los detalles ni emociones de los protagonistas que vivieron el momento del primer amanecer. En las versiones chipaya, en cambio, el narrador situado al interior del texto, va describiendo los hechos con los ojos de aquellos que fueron los testi- 
gos del cambio de época -aquellos que viniendo desde el tiempo de la penumbra iven nacer al Sol! - y sobreviven a esta catástrofe cósmica.

A diferencia de los mitos aymara (Cereceda 1990), donde se plantea la existencia de un primer mundo sin Luna ni Sol, los relatos chipaya nos hablan de un ambiente del pasado definido por una permanente luz lunar, pero con un astro fijo. Los demás detalles de este comienzo son iguales a muchos narrados en otros lugares de los Andes: los chullpa (humanidad anterior) presienten o saben que saldrá el Sol, creen que lo hará por el oeste, y se defienden construyendo casas de muros muy gruesos, con las puertas al este. El Sol sale -y los chipaya aportan aquí un dato incréble- que solo un pueblo que imagina haber estado presente en ese extraordinario acontecer puede precisar: el Sol sale un día sábado del mes de abril. Esta primera humanidad se quema, según una versión "como una lluvia como de fuego, pero lluvia de Sol".

Y aquí empieza la diferencia con los otros relatos de los pueblos no uru. En un lugar en las orillas del río Lauca, llamado Alljata o Pallqa, algunos chullpa -en unas versiones nueve, en otras más de 50- se lanzan al agua para salvarse. Serán los únicos sobrevivientes directos de los chipaya de hoy. Y toda esa situación de tránsito de este pequeño grupo a una ecología nueva, es narrada con gran complejidad. Sabemos, así, que:

"Estaban todo el tiempo como a bañarse, asomados de la cabeza. El agua estaba caliente. Ellos alimentándose de khiwis, pastos, hierbas acuáticas. Después, dice, que en ese primer día, el Sol se entró y salió la Luna. Estaba más fresco, bueno para pasearse".

La narración adquiere un matiz sentimental no presente en las versiones aymara que miran estos acontecimientos desde lejos, cuando el cuenta cuentos cambia de voz para proseguir: "Ellos estaban con mucha tristeza por los que vivían en los cerros... Caminaron para ver a sus compañeros... iY vieron [a] todos muertos!".

En otra versión se narra que van recogiendo los huesos de sus compañeros: "Los tocaban... se deshacían en las manos... todo quemado. iMuy tristes!". Y luego otro dato que solo espectadores de aquel momento podrían relatar: "Después de unos cuantos días, después de una semana, el Sol se alejó y disminuyó el calor".
Los chullpa (que aún no son los chipaya que serán en la humanidad actual) siguen paseando de noche en busca de otros sobrevivientes. No hay nadie. Empiezan a acostumbrarse al calor, comiendo siempre esas hierbas, cazando las aves acuáticas. Antes, sin embargo, habían sido agricultores y sembraban papas en esos cerros hoy secos, porque antes (aunque no había lluvia: los Caballeros no habían llegado aún), caía una llovizna suavecita y estaba tibio. Después de varios años, sucede un nuevo acontecimiento, aparecen los aymara, y en muchas versiones, lo hacen junto con los españoles y curas, e incluso en otras, es el gobierno español el que los trae a esas tierras: "Después, dice, el Gobierno de los españoles... ha colocado aymara en este cerro. Cerro, cerro, gente cristiana siempre... El gobierno colocaba aymara en los cerros" (J. Condori, relato recogido por la autora).

En esos cerros que antes eran chullpa. Para asegurar su posesión antigua sobre esos lugares, el relato dice que: "A uno de esos cerros los chullpa lo llamaban Sawa, por un pasto que allí crece, y por eso nosotros hasta ahora decimos también Sawa, pero los aymara lo llaman Sabaya".

Es precisamente junto a ese cerro que los aymara empiezan a organizar un pueblo y a levantar su iglesia. "Son gente que ha venido del norte y habla otro idioma".

Los chullpa: "Se piensan ¿cómo nos vamos a cristianar nosotros? Han hablado así los chullpa [...]. Como tenían miedo de día, se van de noche a colaborar en la construcción de la torre. A eso de las cuatro o cinco de la mañana, ellos desaparecían ya, se volvían a su estancia".

Pero los aymara construyen con adobe y los chullpa sobrevivientes solo saben hacer pedazos de barro mezclados con paja brava, muy delgados, moldeados a mano, iguales a los que todavía usan las mujeres chipaya para hacer su fogón. Más adelante, los aymara cubrirán este tipo de ladrillos, llamados maa en chipay taku y tan evidentemente chipaya, con sus adobes "para ocultar el trabajo de los gentiles" (gente sin bautizar): "porque estaba tan notable que se pensaron [los aymara]: ellos [los chipaya] pueden decir un día, 'es la obra de nuestros abuelos, es la obra de nuestros antepasados' pueden decir".

Pero el trabajo de los chullpa es visible desde el interior de la torre y los chipaya solían visitarla: "Hasta a mí, cuando era chico, mi papá me ha mostrado". 
Admirados, los aymara, de ver levantarse su torre, se lo comunicaron al párroco, quien ordena: "Deben ser los gentiles [chullpa]. Ellos son sin nombre. Hay que perseguirlos. No conocen ni a Dios ni a la fe cristiana, hay que bautizarlos". Los aymara los vigilan en la noche, los chullpa se asustan y huyen, pero "un abuelito" se hace pescar. El cura lo bautiza con el nombre de Chinu (nudo, en aymara), pero el abuelito no comprende lo que habla el párroco. Los aymara se hacen guiar hacia los otros que nadan en la laguna. Y sucede, luego, un episodio que recuerda notablemente el apresamiento del último Inka Atahualpa, en manos de los españoles: ${ }^{29}$

"Ahí estaban los chullpita ${ }^{30}$ bañándose qalatos [desnudos] en el agua. [Los aymara sueltan al prisionero y le dan una papeleta] 'Esito agarralo'.31 Los otros chullpa lo vieron: 'Es parecido a como han andado las hormigas', dice que dijeron. 'Será letra? Pero nosotros no comprendemos. Para nosotros hormiga [es]', dice que dijeron".

Vuelven en las noches siguientes a levantar la torre hasta que todos se hacen amarrar y encerrar. "El párroco los bautiza Qespis, Perqa, así" (apellidos que se conservan actualmente). Se llevan como obsequio la imagen de Guadalupe para Alljata, donde le construyen una capilla. En agradecimiento por la construcción de la torre, cada uno de los cuatro ayllu aymara les cede un cerro (cerros que les serán quitados luego por los mismos aymara, al mismo tiempo que serán expulsados de Alljata, que tomará el nombre de Capilla Perdida). Los sobrevivientes se van hacia el sur, por la orilla del río. Se asientan en Jilapata, desde donde también son expulsados. Y continúan su peregrinación, cambiando cada vez de lugar hasta que llegan a una islita, Kaal churu (isla de Leña) en medio de lagunas formadas por las aguas del Lauca. "Había peces y totora. Estaba bueno. Cargaditos se llevaron a la Guadalupe y le construyeron su iglesia". Será el asentamiento definitivo del grupo que en épocas toledanas fue la reducción Santa Ana de Chipaya. "Recién, allí, se dividieron en Aransaya y Manasaya" (M. Quispe, relato recogido por la autora).

Aquí el relato plantea una doble sintaxis: primero, con la historia de los Caballeros. Hasta su instalación en Kaal

\footnotetext{
${ }^{29}$ Este punto ha sido muy bien desarrollado por Wachtel (1992).

30 Notemos que el que cuenta habla de ellos con cariño, en diminutivo.

31 "Esito agarralo": Castellano popular boliviano.
}

churu, aquellos antepasados de la transición chullpa/chipaya, no tienen aún una organización social. Como dice otra variante: "Eran un montón, no más, como un solo ayllu". Serán los Santos Caballeros los que, con sus apariciones o caídas, diseñarán simbólicamente las estructuras espaciales y sociales que caracterizarán, más tarde, al pueblo. Luego, la historia del grupo propiamente tal que se desarrollará en esas mismas tierras del relato, no define el momento preciso en que dejan de ser "sobrevivientes" para convertirse en chipaya (recordemos que aquellos que primero sienten llegar a los Caballeros, Juan Machuka y Ramusa Choqo, están comiendo, al parecer, solo khiwi, y son todavía llamados machu en una variante, es decir chullpa). Esta sintaxis se plantea en la dimensión temporal.

Entre la historia chullpa y la historia del saqra, en cambio, se plantea una relación de otra naturaleza. El saqra es perseguido solo después de que sale el sol. Jesucristo y los santos son solares. ¿En qué momento, entonces, alcanza el saqra a cavar la tierra y trasladar las aguas, permitiendo que los antepasados se sumerjan en Alljata, justamente cuando sale el Sol? La relación en el tiempo es ambigua, casi sugiriendo una imposible simultaneidad... Y sin embargo, el río ya debe estar allí para permitir la salvación, planteándose una relación lógica de presunción: el programa narrativo de la historia chullpa exige la existencia del programa narrativo de la persecución del saqra por San Miguel. Esto ocurre porque el escenario del relato chullpa (donde se salvan) es justamente un trecho del curso del Lauca, ya surgido tan trabajosamente en el relato anterior.

De "sujeto transformado" en la historia anterior ese paisaje pasa a ser, ahora, uno de los "sujetos de la transformación" de los antepasados. Si bien los aymara y el cura donan las semillas, las técnicas de construcción, el nombre y el bautismo, es el río, con su abundancia de hierbas y peces, el que permite conservar las técnicas de la recolección y la caza que provienen de la época oscura. Con ese doble legado, los antiguos chullpa darán origen a los chipaya.

Hay una última articulación: con lo que podríamos llamar la semiótica "real" de la existencia del grupo. Capilla Perdida, en Alljata, era justamente uno de los mojones que limitaba, por el norte, y ya históricamente, a las tierras de la comunidad, cuyo límite sur es el Coipasa. ${ }^{32} \mathrm{La}$

${ }_{32}$ Las tierras chipaya fueron reduciéndose cada vez más a conse- 
subsistencia principal del grupo se ha desarrollado a lo largo del curso inferior del Lauca y al interior de ese programa narrativo vivo que es regar las tierras con las aguas del río. De este modo, el espacio creado por la persecución y huida del diablo viene a ser un "don", un objeto de valor que los dioses (el saqra y los santos) otorgaron a los chipaya para que fuera su hábitat.

Pero ese espacio para los chipaya no se formó únicamente en tiempos inmemoriales. Año a año los soqo, hasta hoy, siguen su curso desde el mar al altiplano dibujando finamente una imagen desde el oeste que el saqra dejó solo diseñada a grandes trazos. ¿De qué manera el espacio de los soqo es también un objeto de valor, algo necesario y deseado?

\section{El aporte semántico de los vientos}

Al pasar soplando, los soqo no transforman la geografía que está allí, independientemente de ellos, con su desierto, sus quebradas altas, sus montañas. Tampoco es posible decir que sufren un proceso en su viaje desde el mar al altiplano. Salvo, quizás, aquel cambio entre nacer y morir, que difícilmente explicaría la compleja red de senderos y lugares que se detallan en sus recorridos. ¿Para qué, entonces, ese relato? ¿Dónde reside su sentido? La fijación arbitraria de rutas repetitivas para los soqo no parece tener otro fin que la recreación de un paisaje.

El quehacer de los soqo, su programa narrativo, es ir simplemente desde la costa hacia los lagos y lagunas, el Poopó y el Coipasa. Y al cumplirlo, van estableciendo una dimensión espacial, recordada en el mito, mientras que en el plano de la experiencia práctica, los chipaya han recorrido esos mismos caminos y descansado en esos mismos lugares, desde tiempos inmemoriales. Para ellos no hay, sin embargo, un relato coherente que guarde la memoria de su paso por cada montón de piedras, sus hazañas, sus historias. Se tiene la impresión, así, de que el recorrido de los soqo, con su forzado pasar por sitios donde tal vez hubo antiguos emplazamientos chipaya o por senderos solo conocidos por ellos, intenta quebrar esa frágil distinción entre el plano de lo imaginario donde se desenvuelven los vientos y el plano de lo real, para

cuencia de las presiones de las poblaciones aymara y hoy, Capilla Perdida queda fuera de los límites comunales. De ahí, la calificación de "perdida". permitir que el quehacer de los hombres acceda al nivel de un texto construido.

Sobre un mismo escenario, entonces -en el nivel superficial- vendrían a converger dos programas narrativos distintos, el de los vientos y el de los hombres. El relato mítico parece jugar con un paso fluido entre uno y otro, hasta el punto de que uno de esos muchos viajeros, un día, entra al texto de los soqo y abraza a la señora del viento. Se establece, así, una necesaria relación connotativa: cuando se escucha la historia de los vientos, resuena necesariamente en la memoria, desde su pasado remoto hasta nuestros días, la historia de los hombres.

Y esta connotación trae un curioso efecto a nivel profundo: son los quehaceres de los hombres - sobre esa extensión compartida desde el altiplano al mar- los que dotan de sentido a esos recorridos arbitrarios de los vientos.

¿No bastaría decir que los vientos pasan por la quebrada y las inmediaciones de Chiapa? ¿Por qué recordar ese paso con tantos topónimos como Wichuta, Kayku, Columayo, Jachura? Relatos de los actuales habitantes de Chiapa (de ascendencia aymara) sugieren la presencia de antiguos asentamientos chipaya en esta quebrada.

Cuentan que, en tiempos antes del Sol, allí junto al río, vivían los chullpa. Y cuando se anunció el amanecer:

“...se juntó la gente. ¿A dónde hay agua? Para librarse en el agua... En este río, ahí se tiraron, no más. Alounos se salvaron. Por eso hay generación [gente que desciende de los chullpa] aquí [en Chiapa]. Sobra de gentiles, también unos cuantos de esos tiempos" (relato recogido por G. Martínez en 1982).

Como vemos, los sucesos de Alljata se repiten en Chiapa. Y más aún, de otras frases de este relato parece desprenderse la identidad étnica entre los jaiñas (habitantes de un pueblito muy cerca de Chiapa) y los chipaya: "Jaiña y Chipaya eran uno no más".33

33 Los propios chipaya tienen también relatos sobre posesiones en el alto Chiapa. Y los habitantes de Isluga, hoy un ayllu aymara situado en el altiplano chileno, justo frente a Chipaya, solían decir que los habitantes de Chipaya y Chiapas eran todos sobrevivientes de aquella época oscura. 
¿Antiguos asentamientos chipaya hoy perdidos sea por el mestizaje, sea por el avance de poblaciones aymara? Un pequeño mallku (un bulto de barro representando a un dios tutelar), recordaba también, hasta hace poco, los lazos entre Chipaya y Chiapa. Se trataba de un mallku venerado por una de las familias de la mitad de abajo del ayllu:

"Nuestro mallku más querido era el Pumiri. Un bultito era, detrás de mi casa. Ese Pumiri era muy adorado porque ese Pumiri es un mallku de agua en Chiapa..." (D. Flores, relato recogido por la autora).

Y el caso del mallku Pumiri recuerda el caso del mallku Tira Tirani, que es una de las kamana de los vientos en plena pampa del Tamarugal. Recordemos que el relato lo definía como un mallku, como una puqara de los antepasados. Pero en Chipaya hubo también un mallku, un bulto de barro, con ese mismo nombre. No pudiendo relatar aquí su larga historia, solo queremos mencionar, de paso, la relación semántica que estableció con su homónimo sepultado hoy en el pueblo de La Tirana..$^{34}$ A diferencia de los otros mallku de Chipaya, a esa réplica del Tira Tirani se le suponía - como a aquel del desierto- un origen chullpa. Para marcar este carácter antiguo o primitivo, el Tira Tirani de la comunidad estaba construido solo de champa, que es el pasto duro que crece en el bofedal, y no de barro y adobe como los otros. Y cuando, enojado porque su bulto no estaba ubicado en el lugar que le correspondía ("ese mallku no estaba en situación..."), decide castigar a los chipaya que lo habían construido, y lo hace justamente con la ayuda de los soqo. Soplan tan fuertemente que más de 200 ovejas se ahogan en el Coipasa: "Por culpa de los soqo, por culpa del Tira Tirani".

¿Por qué mallku tan lejanos, apareciendo en sueños o visiones, exigían ser reconstruidos en las tierras de la comunidad? Levantar la morada de un dios tutelar que ya

\footnotetext{
34 Sobre este mallku recogí diversas versiones que resultan apasionantes por la red de relaciones que establecen y que serían tema de otro trabajo: con una puqara de bronce, de origen chullpa, que es vista en sueños. Con champi (aquellos objetos de plata utilizados en la ceremonia de los vientos) que al aparecer en el fondo de una laguna disecada, marcan el lugar al que debe ser trasladado el bulto del Tira Tirani. Por último, con uno de los mallku principales de la comunidad, el "Aviadoro": según algunos relatos, cuando fue destruido el Tira Tirani se trasladó o convirtió en el Aviadoro, forma bajo la cual permaneció hasta la destrucción de los mallku chipaya por el avance de las religiones protestantes.
}

no existe, ¿no es trasladar el lugar, reapropiárselo? ¿Volver a poseer un territorio tal vez perdido por siglos?

Son los relatos de los recorridos de los soqo los que construyen en la memoria un espacio que tiene la tarea de evocar aquel que fue el espacio del grupo o la proyección más allá del hábitat. ${ }^{35}$ Además de los lugares, los soqo pasan por pequeños senderos "por esos caminitos por los cuales sabíamos antes ir a la costa”. En el amplio macizo cordillerano, y en los descensos hacia los valles, cada grupo tiene su propia huella, utilizada una y mil veces. Así, los aymara de Isluga dicen, reconociendo los rastros: "esos son caminos de los chipaya". Los soqo siguen, pues, las rutas étnicas, definiéndose con una identidad chipaya.

A pesar de su ingenuidad, de su carácter salvaje, los vientos se comportan como los otros dioses, como los Caballeros, como el saqra: construyen y donan un espacio que sin ellos no tendría forma, un espacio para el recuerdo y un espacio para visualizar la historia de los hombres, la de antes, la de ahora. Pero los Caballeros también donan parte del espacio y no se parecen a los chipaya. ¿Por qué una mayor intimidad entre vientos y hombres? Es cierto que los soqo son despeinados, polvorientos e insensibles y que su traje no lleva definiciones, es de un solo color impreciso. Pero el corte de este traje es lo que en chipay taku se llama una ira, es decir, el unku o qhawa, la túnica precolombina que aún usan los propios chipaya. Y mascan coca incluso con llijt'a. ${ }^{36}$ También tocan dando vueltas, necesitan ensayar, comen, se casan, entran en tratos de reciprocidad. Hay, pues, una relación ambigua: no son los hombres - los chipaya no podrían donarse a sí mismos un territorio- sin embargo, son como ellos y parecen en nombre de los chipaya, legitimar el derecho a esas tierras entre el altiplano y el mar.

\footnotetext{
35 Los soqo, en su mítico pasar, recorren, también, detalladamente territorios que hoy pertenecen al ayllu aymara de Isluga. Los chipaya cuentan que, en tiempos antiguos, cuando apenas había aymara, ellos eran los dueños de gran parte de esos lugares. Y que incluso el nombre de una estancia, hoy llamada Araquilla, proviene de aara, la quinoa silvestre que alimentaba a los chullpa, sus antepasados. Una familia chipaya habitaba en el ayllu Isluga - hasta pocos años atrás, no sabemos si todavía - en un lugar muy cerca de Aarquilla.

${ }^{36}$ Es curioso que en los documentos coloniales en que se habla de las antiguas ofrendas a los dioses en los Andes, se menciona siempre la coca pero, nunca acompañada con la ceniza que la precipita, la llijt'a o llujt'a en otras regiones, rasgo que humaniza a los soqo.
} 


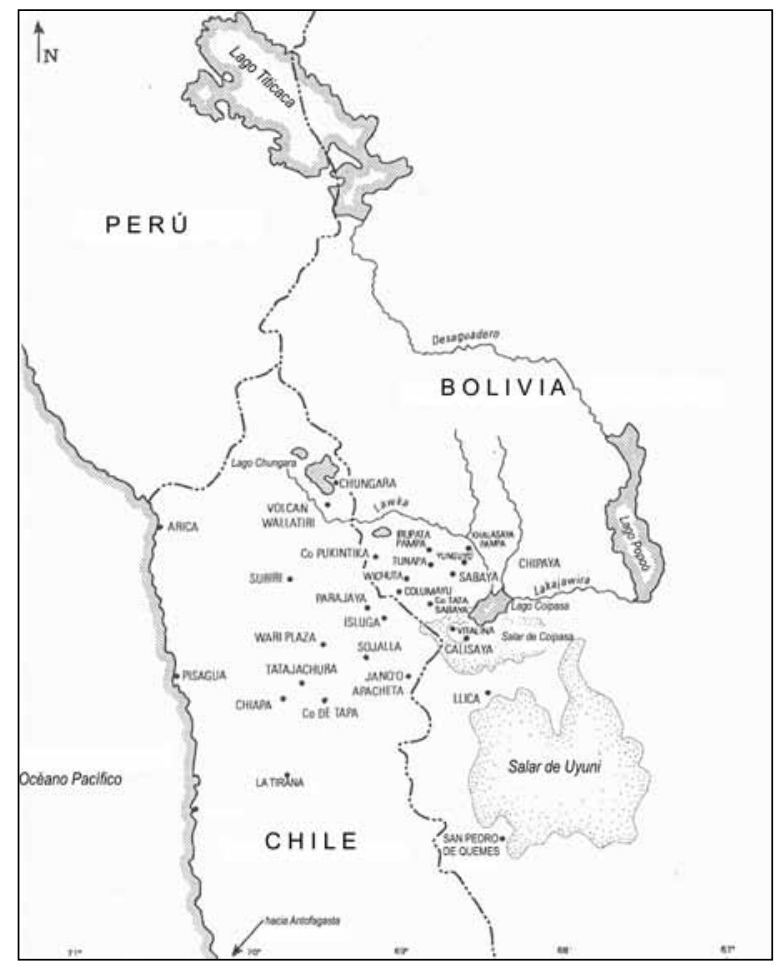

Figura 7. El espacio mítico chipaya, determinado por todas las deidades.

Y el enunciador del mito tiene el buen cuidado de inscribir este espacio dibujado por los vientos al interior de la macroextensión marcada por el saqra. Más aún, obliga a este espacio menor a articularse al espacio mayor del saqra, en los puntos concretos del Chungara, del Coipasa y del Poopó. Como para no dejar dudas de que todas las historias están dibujando una sola y única imagen territorial (Figura 7).

\section{* La estructura semiótica de este mito ESPACIAL}

Los chipaya distinguen bien a sus diferentes personajes sagrados y esa distinción se materializa en las ofrendas que les son dedicadas. ${ }^{37}$ A pesar de que cada uno de ellos

\footnotetext{
${ }^{37}$ A pesar de estas diferencias, los chipaya plantean también relaciones ambiguas y fluidas entre las distintas potencias sagradas no desentrañadas todavía. A los vientos, antiguamente, se les ofrendaba con kupisha, una hierba hedionda (según ellos mismos) de la precordillera chilena. Al faltar ésta, en la ceremonia que describimos, se les ofrendó con copal, el perfume de los mallku, lo que los
}

realiza tareas que le son propias (unos protegiendo a los seres humanos, otros dando riquezas o castigos, o promoviendo la fertilidad, etc.) es posible visualizarlos, en una de sus dimensiones, como sujetos colectivos de un mismo programa. Podemos reconocerlos como sujetos de la transformación de los hombres en lo que se refiere

acerca a los soqo y a otras deidades de "abajo". Los antiguos ritos a los vientos se hacían con cordero de color t'ejllu (manchado), que es la misma combinación cromática que se utiliza para las ceremonias al río Lauca. Luego, saqra y vientos dan vueltas por la izquierda y son ofrendados con la mano izquierda. Por otra parte los mallku, a veces, también tienen saqra y hay que realizar ceremonias especiales para separar ambas deidades. Por último, hay santas como Santa Ana, la patrona, directamente vinculada con las lagunas y no con las nubes. En las ceremonias se invocaba a Santa Qota, es decir, Santa Ana Laguna, y en la iglesia central se guardaban, en vez de los paris angila de la Capilla de San Santiago, dos circulos de plata que representaban al mismo tiempo las lagunas de Chipaya como las lagunas originarias del Lauca, las Paris Qota. El asunto es fascinante y más complejo del que presenta Wachtel (1990) en su gráfico de la cuadratura de los dioses chipaya. Pero un análisis de estas relaciones no entra en el marco de este trabajo: solo tratamos aquí los personajes sagrados como constructores de un espacio. 
a un espacio ecológico geográfico. Después de haberlo perdido todo, en ese preciso instante en que amanece por primera vez, van recibiendo un nuevo ámbito de manos de los dioses. Designando a los dioses por St, a los chipaya por $\mathrm{S}_{1}$ y al espacio como O1, esquematizaríamos este programa como: $\mathrm{St}\left(\mathrm{S}_{1}\right.$ u O 1 - $\mathrm{S}_{1}$ n $\left.\mathrm{O}_{1}\right)$

Ese espacio se plantea, entonces, como un objeto de valor que los personajes sagrados -incluido el aparentemente modesto aporte de los mallku con sus relaciones a larga distancia- han donado a los chipaya. A través de esta estructura, un mito integrador toma forma. Todas las historias y todos los dioses, con toda su diversidad de quehaceres y sentidos, vienen a encontrarse en ese texto, sin palabras propias, de la construcción de un espacio.

Un espacio no solamente para vivir y recordar, sino, además, para ser y conocer. ¿Por qué se extiende hasta el Ti- ticaca a donde raramente se aventuraría hoy un chipaya? ¿Por qué Arica y ese lejano Antofagasta? ¿Por qué incluye al pequeño lago Chungara que los chipaya no conocen y que me hacían describir una y otra vez? Por tantas razones indefinibles, por recuerdos míticos o por historia, por circunstancias diversas, ese espacio se ha conformado también como la gran referencia necesaria a un mundo más amplio que las tierras comunales. El grupo parece definirse en ese espacio: los chipaya son aquellos que hablan de él, que le dan cohesión y que hacen que, más allá de sus límites, se extiendan tierras imprecisas, mundos de otros. De este modo, ese objeto de valor dado por los dioses es, también, un objeto intelectual: la posibilidad de saber y pensar sobre un paisaje. Pero, ino es, al mismo tiempo, un goce emocional? Ningún viajero que subiese a una cumbre, ni ningún pájaro por alto que volase, podría abrazar ese panorama tan vasto y tan querido como el que se construye en la imaginación cuando se escuchan los mitos.

\section{* Referencias citadas}

BOUYSSE-CASSAGNE, T., 1975. Pertenencia étnica, estatus económico y lenguas en Charcas a fines del s. XVI. En Tasa de la visita general de Francisco de Toledo, N. D. Cook (Ed.), pp. 312-328. Universidad Mayor de San Marcos, Lima.

CERECEDA, V., 1990. A partir de los colores de un pájaro... Boletín del Museo Chileno de Arte Precolombino 4: 57-104.

1993. Cette étendue entre l'altiplano et la mer. Un mythe Chipaya hors texte. En Mémoire de la tradition, A. Becquelin y A. Molinié (Eds.), pp. 227-284. Société d'Ethnologie, Nanterre.

DIEZ DE SAN MIGUEL, G., 1964 [1567]. Visita hecha a la Provincia de Chucuito por Garci Diez de San Miguel en el año 1567. Ediciones de la Casa de la Cultura del Perú, Lima.

GREIMAS, A. J. y J. COURTÉS, 1986. Sémiotique. Dictionaire raisonné de la théorie du langage. Hachette Université, París.

MANRÍQUEZ, V., 1999. El término illa y su potencial simbólico en el Tawantinsuyu: Una reflexión acerca de la presencia inca en Caspana (río Loa, desierto de Atacama). Estudios Atacameños 18: 107-118.
MARTÍNEZ, G., 1982 Ms. Notas de campo. Manuscrito en poder de la autora.

MEDINA, J. T., 1952. Los aborígenes de Chile. Fondo Histórico y Bibliográfico José Toribio Medina. MINEDUC / DIBAM, Santiago.

PORTERIE-GUTIÉRREZ, L., 1990. Documentos para el estudio de la lengua chipaya. Amerindia 15: 1-191.

RAMOS, A., 1976. Historia de Nuestra Señora de Copacabana. Empresa Editora Universo, La Paz.

VELLARD, J., 1954. Dieux et parias des Andes. Emile-Paul, París.

WACHTEL, N., 1978. Hommes d'eau: Le problème Uru (XVIe et XVIIe siècle). Annales ESC: 1127-1159.

1990. Le retour des ancêtres. Les indiens Urus de Bolivie XXe XVTe siècle. Essai d'histoire régressive. Gallimard, París.

1992. Note sur le problème des identités collectives dans les Andes meridionales. L'Homme: Revue Française d'Anthropologie. La redécouverte de l'Amérique 122-124:39-52. 